Estudios Constitucionales, Año 16, No 2, 2018, pp. 141-182

ISSN 07180195

Centro de Estudios Constitucionales de Chile Universidad de Talca

"Economía Social de Mercado como sistema constitucional económico colombiano.

Un análisis a partir de la jurisprudencia de la Corte Constitucional”

Andrea Alarcón Peña

\title{
ECONOMÍA SOCIAL DE MERCADO COMO SISTEMA CONSTITUCIONAL ECONÓMICO COLOMBIANO. UN ANÁLISIS A PARTIR DE LA JURISPRUDENCIA DE LA CORTE CONSTITUCIONAL*
}

\author{
Social ECONOMY of THe Market as a COLOMbian eCONOMiC \\ CONSTITUTIONAL SYSTEM. AN ANALYSIS BASED ON THE \\ JURISPRUDENCE OF THE CONSTITUTIONAL COURT
}

\begin{abstract}
Andrea Alarcón Peña*
Universidad Católica de Colombia y Universidad Militar Nueva Granada andreaalarconp@gmail.com
\end{abstract}

RESUMEN: ${ }^{* * *}$ La ordenación de la economía a lo largo de la historia constitucional republicana colombiana (hasta 1991) se ha caracterizado por la inclusión de múltiples artículos con contenido económico en las constituciones que, en todo caso, requerían del desarrollo legislativo para generar contenido vinculante dado el carácter programático de las Constituciones. Esta circunstancia sufrió una modificación relevante con la Norma de 1991 en la que, dado su naciente valor normativo, la Constitución económica cobró una relevancia inusitada. A pesar de la inexistencia formal o expresa de un sistema económico en la Constitución colombiana de 1991, la Corte Constitucional, como intérprete de la Norma Fundamental, ha construido un precedente más o menos consolidado que ha reconocido, materialmente, a la Economía Social de Mercado como el sistema constitucional económico. A esta conclusión se arriba a partir de la interpretación armónica y sistemática del amplio clausulado económico con contenido abierto y flexible de la Norma Fundamental. Este artículo presenta, a través de la construcción de una linea jurisprudencial, el devenir argumentativo que ha permitido adoptar esta posición partiendo de la premisa de la necesidad de un Estado ampliamente interesado

\footnotetext{
* Trabajo recibido el 12 de agosto de 2017 y aprobado el 31 de octubre de 2018.

** Abogada de la Universidad Santo Tomás. Especialista en Derecho Comercial y de los Negocios. Magíster en Derecho Económico de la Universidad Externado de Colombia. Doctora en Estudios jurídicos, Ciencia Política y Criminología de la Universidad de Valencia (España). Investigadora de la Universidad Católica de Colombia. Profesora investigadora de la Universidad Militar Nueva Granada. Código ORCID https://orcid.org/0000-0003-4926-4288.

*** Este capítulo es resultado del proyecto de investigación del año 2017 denominado "Los retos del derecho privado contemporáneo en el contexto del debate constitucional y los nuevos desarrollos de la economía” del Grupo de Investigación en Derecho Privado de la Universidad Católica de Colombia. A su vez recoge algunas de las inquietudes surgidas en el proceso de elaboración de la tesis doctoral que la autora desarrolló en la Universidad de Valencia.
} 
en el devenir económico como elemento esencial para garantizar la satisfacción de los objetivos del Estado Social de Derecho.

ABSTRACT: The organization of the economy throughout the Colombian republican constitutional history (until 1991) has been characterized by the inclusion of multiple articles with economic content in the constitutions that, in any case, required the legislative development to generate binding content given the character programmatic of the Constitutions. This circumstance underwent a relevant modification with the 1991 Standard in which, given its nascent normative value, the Economic Constitution acquired an unusual relevance. Despite the formal or inexistent non-existence of an economic system in the Colombian Constitution of 1991, the Constitutional Court, as interpreter of the Fundamental Standard, has built a more or less consolidated precedent that has materially recognized the Social Market Economy as the economic constitutional system. This conclusion is based on the harmonic and systematic interpretation of the broad economic clauses with open and flexible content of the Fundamental Standard. This article presents, through the construction of a jurisprudential line, argumentative evolution that has made it possible to adopt this position based on the premise of the need for a State that is very interested in economic development as an essential element to guarantee the satisfaction of the objectives of the Social State of Law.

PalABRAS CLAVE: Economía Social de Mercado, Constitución económica, Estado Social de Derecho, Sistema constitucional económico, Intervención estatal.

KEY WORDS: Social Market Economy, Economic Constitution, Social Rule of Law, Economic constitutional system, State intervention.

\section{INTRODUCCIÓN}

La cuestión respecto de la constitucionalización o no de un sistema económico en particular en la norma fundamental colombiana ha ocupado la atención de los constitucionalistas y generado un debate interesante que se hizo palmario en el proceso constituyente de 1991, debido al amplísimo catálogo de cláusulas con contenido económico que fue incorporado en la Constitución colombiana.

Esta circunstancia debe analizarse de cara a la inexistencia de una tradición y una continuidad en el orden constitucional económico. En la tradición constitucional republicana, con antelación a la aprobación de la Constitución de 1991, los constituyentes consideraron que los preceptos de contenido económico no revestían la importancia suficiente para ser incluidos y desarrollados por la Norma Fundamental, otorgando amplias competencias a otras autoridades para que las regularan, mediante vía legislativa y reglamentaria ${ }^{1}$, circunstancia que se veía complementada por la inexistencia de valor normativo de la Constitución que hasta 1991 era una disposición de contenido programático ${ }^{2}$.

1 Palacios (2007 b), pp. 39-55.

2 Corte Constitucional, Sentencia C-820 de 2006, de 4 de octubre de 2006. 
Esta situación varió en el año 1991 cuando el constituyente colombiano, consciente de la importancia de estos asuntos y de la necesidad de dotar de un marco fundamental al ordenamiento económico, incorporó el Título XII del "Régimen económico y de la Hacienda pública", además de artículos diversos, de contenido económico, dispersos a lo largo del texto. No obstante esta motivación, se advierte una absoluta falta de sistemática en el orden expositivo de las normas que integran la Constitución económica.

El sistema constitucional económico colombiano responde a la lógica pluralista que concurrió a su promulgación ${ }^{3}$. Numerosas ideologías fueron partícipes de su construcción y en consecuencia se advierte diversidad: disposiciones con marcada orientación liberal económica y otras que promueven la intervención estatal en la economía. Reconociendo la diversidad y pluralidad de normas con este contenido y la multiplicidad de corrientes ideológicas presentes en el debate constituyente es pertinente preguntarse si establece la Constitución de 1991 algún sistema económico determinado y, si ello es así, cuáles son sus características esenciales.

Responder estas inquietudes exige partir de la premisa de que el proceso constituyente colombiano de 1991 demostró que el Estado no debe ser indiferente a las relaciones económico-sociales. Armoniza esta tendencia con el constitucionalismo propio de la posguerra que permeó en buena parte a los textos constitucionales al incorporar, de forma diversa, la estructuración del orden económico. A consecuencia de esta propensión, la Norma constitucional de 1991 presenta un Estado ampliamente integrado en la vida socio-económica, con la capacidad real -en ocasiones con la obligación- de intervenir e implicarse en determinadas áreas y sectores para lograr materializar la teleología constitucional. Es una Constitución que se aparta de los preceptos del liberalismo clásico demandando acción efectiva de los órganos y ramas del poder político.

Partiendo de la consideración de que dicha Norma, de manera expresa no consigna un sistema económico, corresponde a la Corte Constitucional -máximo intérprete de la misma- determinar, vía jurisprudencia a) si la Norma consigna -materialmente-algún sistema, b) si ese sistema excluye otros y c) cuáles son las características fundamentales del mismo. Partiendo de esta disertación inicial se hace pertinente hacer un análisis de la jurisprudencia constitucional colombiana, a través de la metodología de construcción de línea jurisprudencial, para deter-

3 Cepeda (2005), pp. 335-357. 
minar si, ante la inexistencia expresa de un sistema constitucional económico determinado, el máximo tribunal de la jurisdicción constitucional en su ejercicio de interpretación constitucional ha identificado alguno.

Para lograr este cometido este artículo se estructura en tres partes. La primera de ellas describe las particularidades de la Constitución económica colombiana y las circunstancias que motivaron la indeterminación constitucional expresa por un sistema económico en particular. Posteriormente se identifica la tipología constitucional económica con un análisis de la naturaleza abierta y flexible de las disposiciones que integran la Norma Fundamental. Finaliza el artículo con la estructuración de la línea jurisprudencial que responder al problema jurídico ¿reconoce la Constitución Económica colombiana un sistema particular?

\section{SisteMA ECONÓMICO ACOGIDO POR LA CONSTITUCIÓN COLOMBIANA}

La adopción del modelo de Estado Social de Derecho en Colombia a partir de la Constitución de 1991 (art. 1 CP) permite instalar en la problemática constitucional a la economía colombiana ${ }^{4}$. Sin embargo el constituyente no dio un calificativo expreso al sistema económico colombiano, circunstancia que podría ser interpretada de varias maneras: 1) el constituyente evadió deliberadamente la adopción de una determinación sobre Constitución Económica (quizás debido a las diferencias ideológicas de quienes formaron parte de la Asamblea Nacional Constituyente ${ }^{5}$; 2) el constituyente, considerando el modelo de Estado Social de Derecho, previó que aunque no expresó un sistema de Economía Social de Mercado este resulta ser el único compatible con un sistema democrático como el colombiano, o 3) el constituyente estimó que la inclusión de un amplio catálogo de derechos, libertades y principios - de contenido económico- constituye una hoja de ruta clara al legislador y al gobierno para desarrollar políticas económicas variadas sin que sea pertinente adscribirlo a un sistema en particular.

De estas tres posibilidades resulta claro señalar que la evasión deliberada nunca fue una opción para la Asamblea Nacional Constituyente. Como se de-

\footnotetext{
4 Alarcón (2011), p. 127.

5 Por no ser un estudio historiográfico vale la pena precisar que múltiples autores han desarrollado los antecedentes históricos y particularidades que condujeron a la Asamblea Nacional Constituyente de 1991 y las circunstancias que rodearon la adopción del texto constitucional. Es posible consultar QUiNCHE (2009), pp. 34-58; CEPEDA (2005), p. 367 y ECHEVERRI (2012), pp. 439-461.
} 
sarrollará con posterioridad, las opciones 2 y 3 resultan ajustarse a la posición que desde la jurisprudencia ha desarrollado la Corte Constitucional sobre el subsistema constitucional económico. A su vez, en aplicación del principio de unidad constitucional, no será posible hablar de una Constitución Política y otra Constitución Económica, esta última es parte integral de aquella y satisface los mismos principios, valores y fines que la primera consigna ${ }^{6}$.

Lo que resulta absolutamente claro es que la inexistencia expresa de un sistema económico no puede interpretarse como un deslinde entre economía y Estado y mucho menos como una Constitución indiferente en materia económica ${ }^{7}$. Es abundante el clausulado que en esta materia registra la Norma Fundamental ${ }^{8}$ y que no se limita a establecer campos de acción, sino que

6 Se puede indicar que al aludir al concepto de Constitución Económica se hace mención de dos normas que convergen: Constitución Política y Constitución Económica. Y el problema surge entonces al definir el carácter de aquella respecto de esta. No es posible pensar que el ordenamiento económico se pliega indefectiblemente al ordenamiento político y no le resta alternativa más que ajustar sus disposiciones a las que consigna la Constitución, tampoco indicar que las dos disposiciones discrepan o que no coexisten en un solo cuerpo normativo. El ordenamiento económico alimenta, soporta y coexiste de manera armónica con el político. Por no ser objeto principal de este artículo el análisis del proceso de construcción histórico de la institución Constitución Económica no se hará desarrollo del mismo, sin embargo es posible consultar Schmitt (1998), p. 168; Ehmke (2006), p. 341; Neumann (1987), p. 53 y Maestro (2002), p. 41, quienes desarrollan con precisión el debate que suscitó la relación entre Constitución Política y Constitución Económica.

7 Corte Constitucional, Sentencia C-713 de 1998, 15 de julio de 2008.

8 Aunque no es una relación taxativa la Corte Constitucional en Sentencia C-713 de 1998, de 25 de noviembre de 1998, señaló los principios que, a su entender, conforman el orden económico, así, "(1) la efectividad de los derechos fundamentales, económicos, sociales y culturales, obliga al Estado y a sus autoridades a propiciar un diseño de la economía y de los diferentes procesos sociales que resulte funcional a este propósito; (2) se garantiza la propiedad privada, asociativa y solidaria, pero se establece que ella tiene una función social y ecológica; (3) la calidad de los bienes y servicios ofrecidos y prestados a la comunidad debe ser objeto de regulación legal y de vigilancia pública; (4) el manejo y aprovechamiento de los recursos naturales, lo mismo que el ambiente sano, son elementos que integran el núcleo de derechos colectivos y se convierten por tanto en materia de regulación e intensa protección; (5) las políticas económicas, sociales y ambientales, se articulan a través de los planes de desarrollo, que deben ajustarse al concepto de 'desarrollo sostenible'; (6) se garantiza la libertad económica y la iniciativa privada, dentro de los límites del bien común, el ambiente y el patrimonio cultural de la nación; (7) se promueve el correcto y transparente funcionamiento de los mercados, como garantía y presupuesto de la libertad económica y del eficiente funcionamiento de la economía, para lo cual el Estado debe controlar los abusos que se cometan y que distorsionen sus mecanismos; (8) se ordena al Estado estimular y mantener altos niveles de productividad y competitividad; (9) se señala que la dirección de la economía estará a cargo del Estado y que éste intervendrá por mandato de la ley en el proceso económico con el fin de mejorar la calidad de vida de las personas, la distribución equitativa de oportunidades y la preservación del ambiente sano; (10) la actividad financiera, bursátil, aseguradora y las demás relacionadas con el ahorro se someten a la 
"también reconoce derechos y posibilita la precisión de las potestades que se otorgan al Estado y al particular para ejercer su acción económica" ${ }^{\text {. Los }}$ principios, valores y normas que proclama armonizan claramente con un sistema de Economía Social de Mercado ${ }^{10}$ en el que el mercado libre desempeña un papel fundamental pero la intervención general del Estado en la economía se establece como piedra angular de la actuación estatal ${ }^{11}$ (al considerarse el mecanismo idóneo para corregir falla), propicia el desarrollo económico equitativo y garantiza la supremacía del bien común -que en un sistema liberal de mercado no es prioridad-. Bajo este esquema no es posible predicar confianza en la mano invisible del mercado y mucho menos libertad absoluta para que el Estado intervenga en la economía ${ }^{12}$.

El proceso constitucional colombiano de 1991 demostró que el Estado no debe ser indiferente a las relaciones económico-sociales. Se ajusta a la tendencia del constitucionalismo propio de la posguerra que permeó buena parte de los textos constitucionales al incorporar, de forma diversa, la estructuración del orden económico ${ }^{13}$. La Constitución de 1991 presenta un Estado ampliamente integrado en la vida socioeconómica ${ }^{14}$, con capacidad real -en ocasiones con la obligación- de intervenir y adentrarse en determinadas áreas del mercado para lograr materializar la teleología constitucional. No se trata de una norma que siga los preceptos del liberalismo clásico, que confíe en la mano invisible como motor de la vida socioeconómica, que ceda ante los mandatos del laissez

vigilancia estricta del Estado y a las regulaciones que se dicten; (11) el Estado debe promover la democratización del crédito; (12) los monopolios públicos solo pueden establecerse por la ley como arbitrios rentísticos, con una finalidad de interés público o social; (13) es deber del Estado asegurar la prestación de los servicios públicos a todos los habitantes del territorio nacional; (14) se considera que es objetivo fundamental de la actividad del Estado solucionar las necesidades insatisfechas de salud, educación, saneamiento ambiental y agua potable".

9 SÁNCHeZ (2007), p. 22.

10 Alarcón (2017), p. 102.

11 La Sentencia de la Corte Constitucional, C-265 de 1994, de 2 de junio de 1994, reconoce, por primera vez y de manera expresa, la existencia de un sistema de Economía Social de Mercado en la C.P. que se muestra conforme con la iniciativa privada y la libre actividad económica (art. 333 C.P.) ligada a la dirección general de la economía en cabeza del Estado (art. 334 C.P.).

12 Cidoncha (2004), pp. 109-158.

13 Häberle (1997), p. 25.

14 Torres (2017), pp. 148-176. 
faire $^{15}$ sino una Ley Fundamental que demanda la acción efectiva de los poderes públicos ${ }^{16}$.

Se ha pretendido señalar que, debido a la pluralidad ideológica presente en la Asamblea Nacional Constituyente, las disposiciones de contenido económico de la Norma Fundamental reflejan tal condición y consignan en sus artículos sistemas económicos con orientación diversa, así, el artículo 333 (actividad económica e iniciativa privada libre) es propio de una filosofía de corte liberal y el artículo 334 (dirección general de la economía por parte del Estado y amplias facultades de intervención) corresponde a una norma tendencialmente intervencionista; o como señala Mejía Quintana ${ }^{17}$ se produce la convergencia de dos sistemas políticos: uno de corte neoliberal (producto de la política de apertura y liberalización propia del gobierno de turno) y otro socialdemócrata (propio del modelo de Estado que aquella incorporó), condición que impide asociar sus disposiciones con un sistema económico determinado; sin embargo, tal argumento constituye un intento simplista y erróneo.

Tal como advierte Perry ${ }^{18}$, detenerse en el debate de si la Constitución Económica de 1991 es garantista o intervencionista constituye una misión estéril basada "en un supuesto erróneo y superado: que Estado y mercado son necesariamente

15 Por ello, es posible revisar en la discusión que precedió a la adopción del articulado del Título XII de la Constitución que ésta "en materia económica consagra el sistema de la libre empresa [...] Así mismo prevé que la empresa es la 'base del desarrollo'. Pero agrega que ella 'tiene una función social que implica obligaciones'. No se trata de consagrar el principio del 'laissez faire, laissez passer' y por eso 'la dirección general de la economía estará a cargo del Estado”. Pérez GonzÁlez-Rubio (1991), p. 29.

16 No obstante esta afirmación y la indiscutible modificación en la forma de Estado que se asumió con posterioridad a 1991, SÁCHICA (1991), p. 147, reconoce que el sistema económico colombiano en ese año no experimentó un "viraje deliberado distinto al modelo que traíamos" respecto al año 1936 (reforma constitucional de corte social que incorporó ideales propios del liberalismo) cuando en su decir se podía predicar un sistema de economía mixta. Sin embargo esta afirmación no puede ser aceptada por cuanto la combinación de la protección de libertades económicas propias de un sistema de economía de mercado con matices intervencionistas en ciertos sectores, reconocidos por el autor como definitorios del sistema defendido, no permiten per se predicar la inmutabilidad del sistema económico de 1991 respecto de la modificación de 1936, pues el reconocimiento de un Estado Social de Derecho supuso variaciones importantes respecto a la finalidad de dicha intervención y los objetivos perseguidos por el Estado al poner en marcha planes y políticas públicas. Así, resulta claro que la teleología constitucional propia de la Norma de 1886 sufrió modificaciones importantes respecto a la propia de la Constitución de 1991 por lo que pensar en sistemas económicos afines en ellas resulta contrario a las finalidades de los modelos de Estado reconocidos en una y otra.

17 Mejía (2010), p. 10.

18 Perry (2011). 
antagónicos". Como se advertirá, el sistema constitucional económico posee unas características abiertas y flexibles ${ }^{19}$ que, como precisa la Corte Constitucional, podrían considerarse propias de uno proclive a orientaciones económicas diversas, en el que existe una consideración importante del poder público como agente fundamental dentro de la regulación y desarrollo económico, como un agente clave de justicia social ${ }^{20}$.

Probablemente es la indeterminación de la Constitución respecto a un sistema económico determinado lo que ha permitido al máximo Tribunal Constitucional dictar abundante jurisprudencia que ha desarrollado aspectos fundamentales de la Constitución Económica. Y es precisamente la textura abierta ${ }^{21}$ y flexible de

19 La especial naturaleza de la Constitución en el ordenamiento jurídico colombiano le otorga varias condiciones, una de ellas apunta a la discriminación positiva que de ella se hace como norma superior pues esta no es concibe como igual a las demás, no solo por su carácter superior y prevalente amén del contenido material que registra y que combina cláusulas axiológicas y principios que, se desarrollan legal y judicialmente, y que tienen una "textura abierta", se caracterizan por la "ambigüedad natural del lenguaje" y por la indeterminación de sus normas para "garantizar la estabilidad jurídica y la vocación de proyección en el tiempo de las normas constitucionales". Sentencia C-820 de 2006 Corte Constitucional.

20 Benítez y otros (1991), p. 2.

21 La naturaleza abierta o textura abierta del derecho, en palabras de HART (1995), pp. 168-169, "significa que hay, por cierto, áreas de conducta donde mucho debe dejarse para que sea desarrollado por los tribunales o por los funcionarios que procuran hallar un compromiso, a la luz de las circunstancias, entre los intereses en conflicto, cuyo peso varía de caso a caso. No obstante ello, la vida del derecho consiste en muy gran medida en la orientación o guía, tanto de funcionarios como de los particulares, mediante reglas determinadas que, a diferencia de las aplicaciones de standards variables, no exigen de aquellos una nueva valoración de caso a caso [...] en la zona marginal de las reglas y en los campos que la teoría de los precedentes deja abiertos, los tribunales desempeñan una función productora de reglas". Respecto a la textura abierta de las disposiciones constitucionales, la Corte Constitucional colombiana en diversas sentencias ha reafirmado tal naturaleza, por ejemplo en la Sentencia C-651 de 2003, de 5 de agosto de 2003, reconoció que "debido a la naturaleza del proceso de formación de las constituciones escritas, de la función social y política que desempeñan, y de su vocación de permanencia, éstas suelen tener ciertas características lingüísticas que las diferencian de las demás categorías de textos jurídicos. En particular, suelen utilizar un lenguaje más indeterminado y abierto, en el cual no necesariamente predominan las órdenes ni las formas gramaticales prescriptivas, o cuando ello sí ocurre, no se establecen los órganos competentes. Por supuesto, estas características no son exclusivas de los textos constitucionales, y por el contrario, pueden encontrarse también en otros estatutos jurídicos de diversa naturaleza, aunque la denominada 'textura abierta' o indeterminada del lenguaje es un elemento común de las constituciones contemporáneas. Al ser el resultado de un consenso político y debido a la función social que desempeña la Constitución, el lenguaje constitucional tiene por lo general una textura abierta a diversas interpretaciones. Esta característica, es un factor que incide sobre dos cuestiones fundamentales, lleva a que existan diversas formas de exigir un contenido más o menos amplio, y permite un alto grado de discrecionalidad en cabeza de la autoridad competente para desarrollarlo. En esa medida, la posibilidad de requerir el cumplimiento de una Constitución supone una competencia política que requiere el otorgamiento de amplias facultades al órgano competente, que le permiten incidir directamente sobre la estructura y el 
las disposiciones constitucionales -entre ellas las de contenido económico- las que permiten predicar la condición de fuente del Derecho que tiene la Constitución no solo como un conjunto de deberes cerrados con claros límites negativos respecto de la acción estatal y al contenido del orden jurídico, que demanda cumplimiento y aplicación de las reglas que prescribe la Norma, sino como un conjunto de deberes abiertos "que ordenan un cierto modelo de acción estatal y un cierto proyecto de orden jurídico y cuyo cumplimiento requiere centralmente desarrollo y deliberación" 22 , competencias que le corresponden a todas las autoridades y órganos del poder público que intervienen en la dirección de la Economía y que permiten inferir que el orden jurídico y todo el tratamiento que en materia económica y social registra el Estado colombiano responde a un desarrollo de exigencias constitucionales. En consecuencia, es posible señalar que la apertura y flexibilidad de las disposiciones constitucionales permite al legislador y al juez constitucional contar con un amplísimo margen de interpretación y desarrollo que, en todo caso, tendrá en consideración límites claros dados por la teleología del Estado Social de Derecho.

Al pretender hacer una sistematización de la Constitución Económica colombiana el propósito fundamental consiste en determinar cuáles son los principios estructurales que configuran el orden económico, cuáles son las características que lo componen y cuál es la forma de resolver sus interdependencias. Esta última mención obedece a la existencia de múltiples normas de naturaleza económica dispersas en todo el texto constitucional -caracterizadas por una absoluta falta de sistemática en el orden expositivo- que responden a la necesidad de establecer una estructura constitucional económica. Siguiendo a García Echeverría ${ }^{23}$, la economía necesita de un orden y ese orden puede predicarse desde dos perspectivas: ordenación de los principios, garantías e instituciones y las medidas que permiten su funcionamiento (política económica institucional) y ordenación para la realización de los procesos económicos (política económica del proceso).

\footnotetext{
funcionamiento del Estado". Para ampliar esta característica es posible consultar las sentencias de la Corte Constitucional C-107 de 2013, de 6 de marzo de 2013; Sentencia C-350 de 2009, de 20 de mayo de 2009; Sentencia C-818 de 2005, de 9 de agosto de 2005, y Sentencia C-284 de 2015, de 13 de mayo de 2015 y el interesante texto de Uprimny y Rodríguez (2008), pp. 10 y ss.

22 Aguiló (2004), p. 16.

23 García (1978), p. 21.
} 


\section{Tipología CONSTituCiOnAL ECONÓMICA COLOMBiANA}

Se parte de la consideración de que la Ley Fundamental de manera expresa no consigna un sistema económico determinado, razón por la cual será a su máximo intérprete ${ }^{24}$ a quien le corresponde determinar, vía jurisprudencia, cuál de estos es el que se acoge. La decisión de no adoptar un sistema económico único responde a una consideración adicional, "la economía es coyuntural y cíclica, lo que implica que lo que hoy es cierto en materia económica mañana puede dejar de serlo" 25 , razón por la cual incluir un sistema puede constituir, en futuras oportunidades, camisa de fuerza que restrinja la adopción de determinada política económica, necesaria, en un momento determinado. Se planteó entonces la posibilidad de que las disposiciones económicas constitucionales pudieran tener "contenidos tan variados que bajo los mismos podían englobarse posiciones muy diferentes. Se entendió entonces que las normas de la Constitución Económica eran cláusulas abiertas ${ }^{26}$ cuyo contenido debía ser precisado por el Legislador ordinario y por la Administración de cada momento, por ser ellas las instancias a cargo de quienes se encuentra la orientación de la economía"27.

Previamente a la determinación de lo anterior es preciso partir de la consideración de que la Constitución colombiana de 1991 es normativa y es valorativa. Pero desde el punto de vista económico encontramos una Constitución normativa y abierta, que no constitucionaliza un sistema económico exclusivo ${ }^{28}$ y que

24 Por mandato expreso de la Constitución corresponde a la Corte Constitucional ser la guardiana de su "supremacía e integridad" (art. 241 C.P.), en desarrollo de ese mandato actúa como el "intérprete autorizado por el orden jurídico de lo que está conforme con la Constitución o no" Auto 057 de 2004. En el mismo sentido es posible consultar la Sentencia de la Corte Constitucional C-426 de 2002, de 29 de mayo de 2002, en la que la Corte ha admitido incluso que podría discernir sobre la interpretación que de la misma hacen los jueces de la República, así que si "se le confía la guarda de la integridad y supremacía de la Constitución (C.P. art. 241), su actividad como órgano de control, cuando lo que se impugna es la orientación jurisprudencial dominante de un texto legal, no puede limitarse a la mera confrontación exegética entre éste y el Estatuto Superior, sino que debe extenderse también al plano de la interpretación procediendo a dilucidar los distintos sentidos posibles de los supuestos impugnados, las interpretaciones que resultan intolerables y los efectos jurídicos diversos o equívocos que contrarían la Constitución”. En el mismo sentido las Sentencias C-037 de 1996, de 5 de febrero de 1996 y C-820 de 2006, de 4 de octubre de 2006.

25 AnZOLA (2007), p. 126.

26 Aragón (1995), p. 9.

27 Santaella (2001), p. 86.

28 Autores como Miranda (2016), p. 263, reconocen que el sistema económico acogido es el de ESM al igual que CORTÉs (2009), p. 9. De otra parte LEGUizAmón (2000) afirma que es un modelo de economía mixta y SÁnCHEZ (2001), p. 285, manifiesta que el sistema económico adoptado a partir de la Constitución 
admite políticas económicas diversas con claros límites ${ }^{29}$, en consonancia con la vocación universalista, racional e imparcial de la Constitución.

Considerando la clasificación propuesta por Bassol ${ }^{30}$ sobre la existencia de dos tipos de constituciones económicas -descriptivas y sustancialistas-, es posible indicar que la colombiana satisface las pretensiones de una Constitución descriptiva que no responde a un sistema económico expreso o determinado, pero que incluye un amplio catálogo de disposiciones que, integradas, permiten una valoración en conjunto. Como se desarrollará posteriormente, la Constitución colombiana, siguiendo el sistema constitucional alemán ${ }^{31}$ y español ${ }^{32}$ no preconiza un sistema económico único, sino que se muestra abierta a todas las posibles medidas que armonicen con las normas económicas que en su interior se encuentran.

Si se parte de la base de que la Constitución Económica es un conjunto de normas que ordenan la vida económica social ${ }^{33}$ y establecen el marco jurídico que permite el funcionamiento de la actividad material productiva ${ }^{34}$, esas reglas no pueden ser interpretadas de forma aislada, sino que deben ser entendidas en concordancia con los principios y valores consignados en el Preámbulo, el Título I, los derechos fundamentales, sociales y económicos y las demás normas constitucionales y, como resulta obvio, en concierto con el principio Estado Social de Derecho que por naturaleza condiciona el proceso económico y social.

de 1991 en Colombia es el neoliberal. Sin embargo, esta afirmación de este último autor contradice aquella que expuso en el libro Constitución Económica (2007) en la que afirma que la Constitución no acoge ningún sistema, aunque en capítulo del libro del mismo año, en autoría con IBÁŃEZ (2007a), reconoce la existencia de un sistema constitucional económico de Economía Social de Mercado. Es posible concluir que, a partir de la lectura de los textos y su aparente contradicción, la referencia que al neoliberalismo hace se formula a partir de un análisis de las medidas económicas que se han adoptado en los últimos años en Colombia y que se ajustan a ese sistema. En el mismo sentido UPRIMNY (2002), p. 71 considera que "ha existido una fuerte tensión entre el contenido social de la Constitución y las estrategias de desarrollo que los gobiernos colombianos pusieron en marcha desde 1990" con clara tendencia neoliberal.

29 Uprimny y Rodríguez (2005), p. 24.

30 Bassols (1985), pp. 17-18.

31 PAPIER (1996), pp. 561-612 y STÖBER (1992), pp. 63-68.

32 Es posible mencionar entre otros a Álvarez (2005), p. 157; Menéndez (1985), pp. 33 y ss.; MartínRetortillo (1998), p. 85, y Martín-Retortillo (2000), pp. 149-174.

33 Vergottini (2012), pp. 340-342.

34 Corte Constitucional, Sentencia C-265 de 1994, de 2 de junio de 1994. 
La flexibilidad y apertura del clausulado económico permiten a su vez que el orden económico sea permeable a las modificaciones que se puedan dar respecto a la plataforma programática del partido de gobierno ${ }^{35}$, cambiante por la naturaleza misma de la democracia, sin que exista variación o mutación de sus fundamentos. Se trata de un sistema que puede dar respuesta a problemas propios de momentos históricos diversos y ofrece soluciones a largo plazo; un ordenamiento que permite una fácil adaptación respecto de la realidad económica. La Norma Constitucional Económica, bajo esta perspectiva, se adapta a la realidad sin que se pueda predicar la existencia, para el caso colombiano, de lagunas respecto a las libertades económicas o los criterios de intervención del Estado en la economía.

La flexibilidad y apertura de las disposiciones económicas que consigna la Ley Fundamental se ajusta a la tesis de la indecisión constitucional expresa frente a un sistema económico exclusivo; todas ellas, interpretadas en conjunto permiten concluir en la inexistencia de "una decisión global del constituyente por un determinado sistema económico"36. Aquel trazó los rasgos esenciales del sistema que sirve como lineamiento a las autoridades encargadas de la dirección de la economía para adoptar medidas diversas con un margen de discrecionalidad importante. Y ese margen lo encuentra en el mandato que caracteriza al Estado Social de Derecho orientado a satisfacer el componente social que lo identifica y "realizar la justicia social y la dignidad humana mediante la sujeción de las autoridades públicas a los principios, derechos y deberes sociales de orden constitucional" 37 .

La apertura de las cláusulas que consigna la Norma Fundamental supone un ejercicio de interpretación armónico y sistemático que exige de las autoridades y órganos competentes un análisis que se ajuste a los lineamientos generales que consigna la Constitución y que se convierten en pilares fundamentales que no podrán ser desatendidos so pena de violación a la Norma Fundamental. Es cierto que buena parte de las competencias de desarrollo constitucional se otorgan al legislador, pero esta facultad no es ilimitada, en la medida en que existen sistemas económicos y decisiones legislativas que se encuentran proscritas por

35 ОСНОА (1985), p. 236.

36 Estrada (2002a), pp. 171-198.

37 Corte Constitucional, Sentencia C-1064 de 2001, 10 de octubre de 2001. 
reñir con la teleología y fines del Estado. En consecuencia no podrá considerar el legislador la adopción de un sistema de economía dirigida o economía de mercado pues estos resultan contrarios al sentir constitucional ${ }^{38}$.

En este sentido resulta claro que el marco económico que contempla la Constitución supone una doble perspectiva: una garantista y otra correctora. La primera de ellas destaca en la protección y promoción de las libertades económicas necesarias para el funcionamiento de una economía de mercado (propiedad privada, libertad de empresa, libre competencia, etc.); la restante enfatiza el papel de la economía como instrumento para alcanzar el bienestar social e individual poniendo de presente principios como la igualdad y la solidaridad y valores como la justicia y la paz social ${ }^{39}$.

Se establece entonces una clara hoja de ruta para el Estado que deberá adoptar todas las medidas necesarias para obtener esos cometidos, circunstancia que impone a la vez obligaciones para los individuos orientadas a promover la responsabilidad por su propio bienestar. La realización de los fines generales del Estado y en concreto el "dar pleno empleo a los recursos humanos y asegurar que todas las personas, en particular las de menores ingresos, tengan acceso efectivo a los bienes y servicios básicos" (art. 334 inc. 2 C.P.), además de promover la competitividad, la productividad y el desarrollo armónico de las regiones ${ }^{40}$, serán faros orientadores de la actividad interventora que tendrá aquel en la economía. Es por ello que, entre otros, la protección del trabajo (art. 53 C.P.) y la responsabilidad del Estado para garantizar el pleno empleo (art. 334 inc. $2^{\circ}$ C.P.) se constituyen en objetivos de la Constitución Económica y en virtud de tal mandato al Estado le corresponde "por medio de la política económica y social [...] ser agente de estímulo a la creación de empleo en el mercado laboral, todo ello dentro del marco constitucional de protección especial al trabajo" ${ }^{41}$.

El desarrollo de la libertad económica (art. 334 C.P.) -libertad de empresa y libre iniciativa privada ${ }^{42}$ - corresponde a los agentes públicos y privados que, para poderla desplegar, necesitan de un marco normativo que proteja el

38 Corte Constitucional, Sentencia C-265 de 1994, de 2 de junio de 1994.

39 García y Almonacid (1999), p. 148.

40 Corte Constitucional, Sentencia C-830 de 2010, 20 de octubre de 2010.

41 Corte Constitucional, Sentencia C-776 de 2003, 9 de septiembre de 2003.

42 Corte Constitucional, Sentencia C-616 de 2001, 13 de junio de 2001. 
derecho a la propiedad y los procesos de intercambio y que exige un mercado en el que la libre competencia sea una constante -premisa fundamental de una ESM-.

Sin embargo, el mercado, que en condiciones libres no genera equidad y redistribución de los beneficios, excluye a aquellos que se encuentran en condición de desigualdad y genera graves perturbaciones a la teleología constitucional, es allí donde el Estado, regente general de la economía y en cumplimiento de su papel económico, social y político, interviene como un redistribuidor de recursos ${ }^{43}$. No obstante esta dirección, los individuos desempeñan un papel fundamental en esa ordenación, al tenor del principio constitucional de solidaridad los lazos de ayuda, colaboración y cooperación entre ciudadanos resultan fundamentales para dar sostenibilidad a la Constitución Económica.

Lo planteado hasta ahora supone la posibilidad para el Estado de intervenir en la Economía, sin embargo, tales intervenciones no pueden ir en contradicción con el principio de subsidiariedad que gobierna el sistema de ESM, así ha señalado la Corte Constitucional ${ }^{44}$ "el Estado no requiere intervenir cuando los individuos se basten a sí mismos. El apoyo del Estado se requiere allí en donde se hace imposible o demasiado difícil poder satisfacer de manera eficaz las necesidades básicas" ${ }^{4}$. La protección del principio de libertad en el ESD exige el respeto por la autodeterminación y autorrealización del individuo que, en casos de necesidad e imposibilidad material de proveerse sus propias condi-

43 Corte Constitucional, Sentencia C-1107 de 2001, 24 de octubre de 2001.

44 Corte Constitucional, Sentencia C-983 de 2005, 26 de septiembre de 2005.

45 Resulta de absoluto interés en este punto hacer una discriminación respecto al sentido en que se usa la subsidiariedad en este análisis. Es posible delimitar este principio en dos sentidos: subsidiariedad institucional y subsidiariedad estatal, al tenor de ArIŃo OrTIZ (2003), p. 161. Para el presente estudio la subsidiariedad estatal apunta a la imposibilidad, para el Estado, de intervenir para satisfacer necesidades de los individuos cuando estos se encuentren en posibilidades materiales de hacerlo -en clara armonía con la Doctrina Social de la Iglesia-. La restante acepción -que no será usada en el presente estudio- permite concebirla como uno de los principios que rigen la actuación administrativa de los diversos niveles territoriales; de conformidad con el artículo 288 de la Constitución "las competencias atribuidas a los distintos niveles territoriales serán ejercidas conforme a los principios de coordinación, concurrencia y subsidiariedad en los términos que establezca la ley”. El principio de subsidiariedad, en los términos del artículo en mención y de acuerdo al contenido de la Sentencia de la Corte Constitucional C-517 de 1992, de 15 de septiembre de 1992, supone que "únicamente en caso de no poder ejercer determinada función independientemente deberá apelar a niveles superiores", (refiriéndose a los municipios, pero aplicable a las demás entidades territoriales). 
ciones que garanticen la satisfacción de su dignidad ${ }^{46}$, legitiman la actuación e intervención del Estado ${ }^{47}$.

\section{HaCia la CONSOlidación de UN PRECEDENTE}

Hechas estas precisiones, resulta acertado indicar que la determinación del sistema constitucional económico que adoptó la Constitución de 1991 ha sido una tarea de la Corte Constitucional como su intérprete autorizada, la que resuelve sus aparentes ambigüedades y contradicciones al acudir a una interpretación sistemática de la Norma como un todo. Toda su labor, sin embargo, no supone trasladar a la Corte funciones de constituyente primario al permitirle concretar las disposiciones económicas de contenido abierto y flexible que aquel, en su momento, consideró.

La tarea del Tribunal Constitucional se halla ligada a la armonización que de las mismas debe hacer en el marco del modelo de Estado Social de Derecho, que fija un norte claro respecto de los objetivos y metas que deben guiar las políticas y decisiones de los diversos órganos y ramas del poder público. Ha sido este órgano jurisdiccional el que, en abundante jurisprudencia, ha desarrollado una línea respecto al problema jurídico que plantea el presente epígrafe de la tesis: ¿reconoce la Constitución Económica colombiana un sistema particular? ${ }^{48}$ :

46 Torres (2012), p. 35.

47 En el mismo sentido la Corte Constitucional en Sentencia T-028 de 1994, de 31 de enero de 1994, señaló que "el artículo 336 superior, establece, como finalidad social primordial del Estado, la de buscar un mejoramiento en las condiciones de vida de la población. Sin embargo, no puede considerarse que esta disposición establezca que las autoridades estatales son las únicas responsables de la obligación de realizar todas las gestiones económicas, políticas y sociales para alcanzar este fin, pues no puede olvidarse que a cada uno de los asociados se le asigna -en aras del equilibrio social- el compromiso de colaborar en el mismo sentido; particularmente si se tiene en consideración que es deber constitucional de todo colombiano el de obrar conforme al principio de solidaridad social, el de respetar los derechos ajenos y no abusar de los propios, y el de velar por la conservación del medio ambiente (art. 95 núms. $1^{\circ}, 2^{\circ}$ y $8^{\circ}$ )” y previamente en Sentencia T-236 de 1993 indicó, en el mismo sentido, que "la sociedad participa en el quehacer social del Estado".

48 Para revisar la jurisprudencia que sobre el sistema económico adopta la Constitución de 1991 se usó la metodología de línea jurisprudencial que describe López en su texto Interpretación Constitucional (2006), pp. 114 y ss. Para lograr tal cometido se identificó como sentencia arquimédica la Sentencia de la Corte Constitucional C-830 de 2010 y a partir de ella se construyó la línea. Esta metodología fue escogida pues permite hacer una revisión sistemática y ordenada de la abundante producción jurisprudencial de la Corte. 


\begin{tabular}{|c|c|c|}
\hline Polo 1 & $\begin{array}{l}\text { Problema jurídico: ¡reconoce } \\
\text { la Constitución Económica } \\
\text { colombiana un sistema } \\
\text { económico particular? }\end{array}$ & Polo 2 \\
\hline $\begin{array}{l}\text { La Carta Fundamental } \\
\text { no consigna un sistema } \\
\text { económico determinado } \\
\text { que limite la adopción } \\
\text { de medidas económicas } \\
\text { o sociales, es flexible } \\
\text { frente a cualquier sistema } \\
\text { económico que se ajuste } \\
\text { a los principios y fines del } \\
\text { ESD }\end{array}$ & $\begin{array}{l}\text { T-425 de } 1992 \\
\text { T-505 de } 1992 \\
\text { T-380 de } 1993 \\
\text { C-074 de } 1993 \\
\text { C-265 de } 1994 \\
\text { C-524 de } 1995 \\
\text { T-308 de } 1995 \\
\text { C-398 de } 1995 \\
\text { C-535 de } 1997 \\
\text { C-478 de } 1998 \\
\text { C-713 de } 1998 \\
\text { C-332 de } 2000 \\
\text { C-616 de } 2001 \\
\text { C-815 de } 2001 \\
\text { C-1064 de } 2001 \\
\text { C-615 de } 2002 \\
\text { C-865 de } 2004 \\
\text { C-392 de } 2007 \\
\text { C-1041 de } 2007 \\
\text { C-228 de } 2010 \\
\text { C-830 de } 2010 \\
\text { C-978 de } 2010 \\
\text { C-186 de } 2011 \\
\text { C-263 de } 2011 \\
\text { C-197 de } 2012 \\
\text { C-288 de } 2012 \\
\text { C-644 de } 2012 \\
\text { C-909 de } 2012 \\
\text { C-263 de } 2013 \\
\text { C-313 de } 2013 \\
\text { C-837 de } 2013 \\
\text { C-148 de } 2015 \\
\text { C-035 de } 2016 \\
\text { C-032 de } 2017\end{array}$ & $\begin{array}{l}\text { La Constitución Económica } \\
\text { colombiana reconoce, } \\
\text { materialmente, un sistema } \\
\text { de Economía Social de } \\
\text { Mercado }\end{array}$ \\
\hline
\end{tabular}

Como se advierte, al tenor de la interpretación del sistema económico constitucional que realiza la Corte Constitucional es posible advertir la concurrencia de tres posiciones al respecto: 


\subsection{Neutralidad constitucional en materia económica}

Esta posición plantea la posibilidad de que las disposiciones económicas constitucionales puedan tener "contenidos tan variados que bajo los mismos podían englobar posiciones muy diferentes" así, "se entendió [...] que las normas de la Constitución Económica eran cláusulas abiertas cuyo contenido debía ser precisado por el Legislador ordinario y por la Administración de cada momento, por ser ellas las instancias a cargo de quienes se encuentra la orientación de la economía" 49 .

Es a partir de esta interpretación del orden constitucional económico que surge la tesis de la "neutralidad económica" de la Constitución. Para esta, las constituciones describen de manera abierta y flexible clausulado de contenido económico cuyo contenido podría ajustarse a sistemas económicos determinados que no necesariamente excluyen a otros. Es decir que se reconoce la adscripción del texto a ciertos sistemas económicos excluyendo otros tantos. Esta mención parte de la base de la constitucionalización de la economía sin apegarse a un sistema económico determinado, sin la necesidad de remisión expresa a un sistema en particular pero abriendo la posibilidad a sistemas varios que armonicen con la interpretación que como un todo se hace del texto. Una Constitución neutra respecto a un sistema económico determinado o único, no neutra respecto a la ordenación de la vida económica, por ello se comprende la necesidad de incorporar disposiciones de ordenación económica en la Constitución sin que, necesariamente se constitucionalice un sistema económico único y determinado que presente problemas respecto a su efectividad y realización material.

Esta primera tesis permite la libertad para el legislador y el ejecutivo de desarrollar normas y políticas públicas de contenido económico, con independencia de un sistema económico predeterminado, considerando principios constitucionales generales. En palabras de Hesse "la Constitución también puede tener interés en no someter a normas jurídicas un determinado espacio vital, o bien hacerlo solo bajo algunos aspectos: determinadas cuestiones, como, por ejemplo, la Constitución Económica, la Norma Fundamental los deja abiertos al objeto de dejar en ellos libre espacio a la discusión, decisión y configuración" 50 .

Si se parte de la base de que las constituciones se caracterizan por tener una estructura abierta, dinámica y fragmentaria, es posible comprender con facili-

49 Santaella (2001), p. 86.

50 Hesse (1983), p. 19. 
dad que algunas "cuestiones particulares han quedado conscientemente abiertas, precisamente para que sean resueltas en una libre confrontación política, como la configuración concreta del orden económico y social" 51 . Esta estructura dinámica responde a la manifestación de una situación histórica cambiante, que necesita contemporización, y que solo en la elasticidad de sus normas podrá encontrar vocación de permanencia y perpetuidad.

En este contexto argumentativo es pertinente señalar que la Carta Fundamental colombiana no consigna un sistema económico determinado que limite la adopción de medidas económicas o sociales ${ }^{52}$. Se entiende que la Constitución Económica se encuentra integrada por un agregado de disposiciones que constituyen un marco general de regulación económica que deben ser interpretadas de manera sistemática, integral y armónica con la consideración del modelo de Estado Social de Derecho que reconoce aquella y que parte del reconocimiento de un amplio catálogo de principios, valores y normas que se constituyen en fundamentos y, a la vez, límites de la actuación de todos los órganos del Estado. Ese clausulado, sin embargo, atendiendo a la naturaleza democrática y pluralista de la Constitución impide que se constitucionalice un sistema económico determinado, excluyendo opciones diversas que, en todo caso, deben ser compatibles y armónicas con el grueso de las disposiciones, de contenido abierto y flexible.

La neutralidad del texto, sin embargo, no permite que cualquier modelo o sistema económico sea aplicado al precisar que cualquier actuación de los involucrados en toma de decisiones económicas debe respetar el valor normativo de la Constitución y los objetivos que persigue, por ello es posible que el legislador y el Ejecutivo pueden adelantar, de conformidad con el principio democrático, variadas políticas económicas, "siempre y cuando ellas tiendan de manera razonable a hacer operantes los principios rectores de la actividad económica y social del Estado y velar por los derechos constitucionales" 53 .

La adopción de cualquier decisión en ese sentido se produce a través de claros instrumentos de intervención en el mundo social y económico que pretenden superar y corregir los desequilibrios y desigualdades en pro de buscar la eficaz materialización del Estado Social de Derecho. A su vez, los ciudadanos asumen una

\footnotetext{
51 SCHNEIDER [1991 (1983)], p. 73.

52 Esta posición se advierte entre otras, en las Sentencias de la Corte Constitucional T-380 de 1993, de 13 de septiembre de 1993; C-074 de 1993, de 25 de febrero de 1993; C-478 de 1998, de 9 de septiembre de 1998; C-288 de 2012, de 18 de abril de 2012, y C-644 de 2012, de 23 de agosto de 2012.

53 Corte Constitucional, Sentencia C-478 de 1998, de 9 de septiembre de 1998.
} 
serie de deberes y obligaciones consigo mismos -como responsables de su propio proyecto de vida y realización personal-y con sus congéneres -solidaridad- que generan un entramado de relaciones que ya no se comprenderán en dirección al Estado solamente sino en relación con los demás, en esa medida las obligaciones de tributación - progresiva- y equidad resultan un componente fundamental de la responsabilidad social que deben satisfacer ${ }^{54}$.

Bajo esta perspectiva el marco general de regulación económica es visible en la Constitución, sin embargo la pretensión de permanencia del texto y su carácter abierto y flexible no podría acompasarse con un sistema económico restringido e inamovible que impida que cualquier ideología pueda tener cobijo en el régimen constitucional económico. Por lo anterior es posible señalar que la Constitución Económica, dada la apertura y flexibilidad de sus disposiciones podrá ser compatible con sistemas económicos diversos, siempre y cuando aquel se "muestre apto para la consecución de los fines esenciales del Estado y la vigencia de la cláusula de ESDD"55.

Esta previsión, sin embargo, debe armonizarse con la imposibilidad de que esos posibles sistemas económicos alternativos vulneren los principios y valores del orden constitucional económico ${ }^{56}$. La legitimidad para fijar esas posibilidades se encuentra en el legislador por ser el competente para expedir leyes de intervención económica, para que con un amplio margen discrecional defina el sistema constitucional económico pertinente, dependiendo de las circunstancias sociales y económicas del momento, así se entiende que el orden económico constitucional "es ante todo un mandato de configuración legislativa y que por lo tanto la Constitución es neutra desde el punto de vista de la fijación de modelos económicos, pues dicha tarea le corresponde establecerla a la ley. Lo anterior se ha reconocido así, porque es el Congreso de la República como Corporación Pública y como poder legislativo, cuya configuración constitucional favorece el debate equilibrado

\footnotetext{
54 La Corte Constitucional en Sentencia C-776 de 2003, 9 de septiembre de 2003, señaló que la vida en sociedad implica una serie de derechos y deberes que se hallan atados a criterios económicos que consultan las circunstancias de prosperidad y carencia de algunos individuos frente a otros. El art. 95 núm. 9 de la C.P. dispone que es un deber de los ciudadanos contribuir al financiamiento de los gastos e inversiones del Estado, para poder cumplir con los fines del Estado en condiciones de solidaridad, por ello, y al tenor de la Sentencia de la Corte Constitucional, C-080 de 1996, de 29 de febrero de 1996, el sistema tributario es "un presupuesto esencial de cualquier organización política, de cualquier Estado, [...] a través del cual éste pueda obtener los recursos necesarios para su mantenimiento, fortalecimiento y propia subsistencia".

55 Corte Constitucional, Sentencia C-288 de 2012, 18 de abril de 2012.

56 Como indica Tomás y Valiente (1994), pp. 645-646, esos principios y valores no son simple "música celestial", sino normas positivas dotadas de obligatoriedad.
} 
de mayorías y minorías, la deliberación pluralista, el foro idóneo para establecer las definiciones de cada sector e imponer, según sus exigencias, los aspectos de coyuntura o estructura que determine la situación económica por atender" ${ }^{57}$.

Esta posición debe ser moderada con las limitaciones que el valor normativo de la Constitución impone a la actividad de todos los órganos del poder público en sus actuaciones, al asumir la Norma un carácter vinculante genera para todos los órganos la obligación de respetar sus disposiciones y abstenerse de adoptar determinaciones en su contra. Bajo esta premisa el legislador no podrá disponer un sistema de economía dirigida y mucho menos uno de economía liberal de mercado pues los dos resultan ser contrarios al conjunto de cláusulas superiores, además de que una disposición en ese sentido podría sustituir la Constitución, facultad que no le está dada a aquel.

En conclusión, respecto a este primer ítem, es claro que la neutralidad constitucional respecto al sistema económico permite la armonización del clausulado con varios sistemas económicos que resulten acordes con la teleología de la Norma Fundamental y el modelo de Estado que esta adopta.

\subsection{Interpretación armónica de sus disposiciones sin la posibilidad de predicar neutralidad ni adscripción a un sistema económico determinado}

En esa medida se supera la tradicional separación que entre economía y Estado existía garantizando que "el Estado Social de Derecho, los principios de dignidad humana y solidaridad social, el fin esencial de promover la prosperidad general y garantizar la efectividad de los derechos, deberes y principios constitucionales y el derecho fundamental a la igualdad de oportunidades" 58 guíen la interpretación que se hará de la Constitución Económica e irradie todos los ámbitos en que se produce su ordenación (propiedad privada, libertad de empresa, explotación de recursos, producción, distribución, utilización y consumo de bienes y servicios, régimen impositivo, presupuestal y de gasto público) ${ }^{59}$. Esta medida supone el

\footnotetext{
57 Corte Constitucional, Sentencia C-644 de 2012, de 23 de agosto de 2012.

58 Corte Constitucional, Sentencia T-505 de 1992, de 28 de agosto de 1992.

59 Esta posición se advierte también en la Sentencia de la Corte Constitucional T-425 de 1992, de 24 de junio de 1992; Sentencia T-368 de 1995, de 24 de agosto de 1995; Sentencia C-398 de 1995, de 7 de septiembre de 1995; Sentencia C-713 de 1998, de 25 de noviembre de 1998; Sentencia C-332 de 2000, de 22 de marzo de 2000; Sentencia C-1064 de 2001, de 10 de octubre de 2001; Sentencia C-392 de 2007,
} 
no reconocimiento de un sistema específico, ni la pretensión de armonizarlo o enmarcarlo en uno determinado pues la naturaleza misma de las disposiciones no permite esa armonización.

Se trata de un catálogo amplio, de un documento que solo consigna principios y valores y que no tiene la pretensión de constitucionalizar ningún sistema económico o mostrarse abierto a cualquiera ${ }^{60}$. Bajo esta perspectiva se excluye la posibilidad de otorgar valor normativo a un sistema económico determinado y se centra en la primacía "del Estado Social de Derecho, los principios de dignidad humana y de solidaridad social, el fin esencial de promover la prosperidad general y garantizar la efectividad de los derechos, deberes y principios constitucionales y el derecho fundamental a la igualdad de oportunidades" 61 como referentes y criterios únicos de interpretación de las disposiciones de contenido económico de la Constitución, así, el amplio margen de configuración normativa de un sistema que se reconoce al legislador en la posición de la neutralidad queda reducida pues todo el clausulado "en su conjunto conforma un orden que se erige en patrón de validez constitucional de las políticas que se formulen y ejecuten por parte de los órganos del Estado y, al mismo tiempo, indica a éstos el sentido que debe inspirar el ejercicio diario de sus competencias"62.

La Sentencia C-074 de 1993 precisa con absoluta claridad la tesis de la no neutralidad ${ }^{63}$ al señalar que "el marco constitucional otorga a los actores políticos un amplio margen de libertad, al interior del cual es posible diseñar modelos económicos alternativos. Pero dichos modelos deben, en todo caso, estar encaminados a la realización de los valores que consagra la Carta, a hacer operantes

de 23 de mayo de 2007; Sentencia C-1041 de 2007, de 4 de diciembre de 2007, y Sentencia C-186 de 2011, de 16 de marzo de 2011.

60 Aunque no ha sido expresada por la Corte Constitucional, vale la pena mencionar que esta posición encuentra un referente importante en la doctrina española, así DuQue (1977), p. 58, reconoce que las Constituciones neutras no necesariamente admiten un sistema económico que se ajuste a las variadas disposiciones constitucionales, es posible que no admitan ningún modelo económico.

61 Corte Constitucional, Sentencia T-505 de 1992, de 28 de agosto de 1992.

62 Corte Constitucional, Sentencia C-713 de 1998, de 25 de noviembre de 1998.

63 La sentencia en mención predica la neutralidad constitucional en materia económica, pero en un epígrafe de las consideraciones señala que "no caben, pues, en el sistema jurídico colombiano, proyectos o normas discriminatorias o que vulneren la igualdad de oportunidades, o tiendan a desproteger la libertad de empresa dentro del marco de una economía social de mercado". Esta aparente contradicción en su argumentación no resulta en principio lógica. Sin embargo, la lectura integral de las consideraciones permite predicar que la sentencia orienta su ratio decidenci hacia la neutralidad económica constitucional. 
los principios rectores de la actividad económica y social del Estado y velar por la efectividad de los derechos constitucionales".

Esta posición no dista mucho de la primera, su principal diferencia apunta a la inexistencia de la opción para adecuarlo a un sistema o permitir a algún órgano del poder la determinación del mismo vía legislación o poder reglamentario. Parte de la negación de una neutralidad económica en materia constitucional al considerar que no existe tendencia a cualquier sistema y que no resulta posible aplicar cualquiera pues existen claros límites impuestos que condicionan la adopción de cualquier medida, en esa medida no es posible vincular el sistema constitucional económico con alguno en particular. Se parte de la base de que las normas que integran el orden constitucional económico constituyen patrón de validez de todas las políticas y medidas que se formulen y ejecuten en materia económica e imponen un criterio que determina el despliegue de sus competencias.

\subsection{Reconocimiento material de un sistema de Economía Social de Mercado ${ }^{64}$}

Los diversos elementos que consigna la Constitución Económica permiten identificar su sistema económico con el de una ESM ${ }^{65}$. Este sistema incluso

64 Esta posición se advierte en las Sentencias de la Corte Constitucional C-265 de 1994, de 2 de junio de 1994, (en donde reconoce un sistema de economía de mercado, pero la explicación de sus elementos permiten identificar un sistema de ESM); Sentencia C-524 de 1995, de 16 de noviembre de 1995, (aunque en esta no se menciona con exactitud la expresión ESM si se indica que el sistema es de economía de mercado con la posibilidad para el Estado de intervenir en la economía para lograr los fines que el Estado Social de Derecho persigue); Sentencia C-535 de 1997, de 23 de octubre de 1997; Sentencia C-616 de 2001, de 13 de junio de 2001; Sentencia C-815 de 2001, de 2 de agosto de 2001; Sentencia C-615 de 2002, de 8 de agosto de 2002; Sentencia C- 830 de 2010, de 20 de octubre de 2010; Sentencia C-228 de 2010, de 24 de marzo de 2010; Sentencia C-978 de 2010, de 1 de diciembre de 2010; Sentencia C-263 de 2011, de 6 de abril de 2011; Sentencia C-909 de 2012, de 7 de noviembre de 2012; Sentencia C-263 de 2013, de 8 de mayo de 2013; Sentencia C-148 de 2015, de 7 de abril de 2015, y Sentencia C-035 de 2016, de 8 de febrero de 2016. Aunque la línea jurisprudencial se ha construido con decisiones de la Corte Constitucional, es preciso señalar que esta posición encuentra soporte en pronunciamientos del Consejo de Estado en los que este tribunal ha reconocido -siguiendo la línea del Tribunal Constitucional- que la Economía Social de Mercado es el sistema económico constitucional colombiano, es posible advertir esta postura en sentencias de la Sección tercera. 4 de septiembre de 2015. Rad. 11001-03-26-000-201500103-00 (54549) M.P. Santofimio, Jaime Orlando; Sección Tercera. 9 de julio de 2014. Rad. 6600123-31-000-2009-00087-02 (47830) M.P. Santofimio, Jaime Orlando; Sección Tercera. 21 de febrero de 2007. 25000-23-25-000-2004-00413-01(AP). M.P. Fajardo Gómez, Mauricio; Sección tercera. Rad. 25000-23-27-000-2004-00888-01(AP). M.P. Correa Palacio, Ruth Stella y; Sección Tercera Rad. 2500023-26-000-2000-01335-01 (28.505) M.P. Santofimio Gamboa, Jaime Orlando.

65 LÓPEZ (2017), pp. 151-174. 
ha sido expresamente definido por la Corte Constitucional que en sentencia C-865 de 2004 lo definió como el sistema "según la cual las reglas de la oferta y la demanda deben estar al servicio del progreso y desarrollo económico de la Nación”. Se parte de la consideración de que en la Constitución Económica colombiana un sistema de economía dirigida no podrá armonizar con las garantías y derechos que en materia económica consigna la Norma, propiedad privada (art. 58 C.P.), libertad de empresa (art. 334 C.P.) y libre competencia económica (art. 333 C.P.), pero tampoco se articulará con un sistema de economía de mercado que excluye la dirección general de la economía en cabeza del Estado y las intervenciones que este realiza amparado en el elemento solidaridad que legitima su actuar para promover las condiciones sociales y económicas básicas para el desarrollo autónomo de las personas.

Esa intervención además se ajusta a la necesidad de garantizar la supremacía del bien común y armonizar el interés privado de quienes participan en el mercado con el interés general ${ }^{66}$, para lograr la satisfacción de las necesidades de toda la población "en condiciones de equidad y con el fin de conseguir el mejoramiento de la calidad de vida de los habitantes, la distribución equitativa de las oportunidades y los beneficios del desarrollo y la preservación de un ambiente sano" 67 , permitiendo ajustar el sistema colombiano con el de Economía Social de Mercado propuesto en Alemania en la primera mitad del siglo XX al asignarle al Estado la obligación de intervenir en el mercado con el fin de corregir las fallas que se presentan y que se constituyen en barreras de acceso a las personas que se encuentran en condiciones de desigualdad y desequilibrio.

El constituyente partió del reconocimiento de la condición de desigualdad en que se encuentran los ciudadanos, circunstancia que condiciona su acceso al mercado y el disfrute real de las múltiples opciones que este ofrece -amén de constituirse en escenario en que se demandan servicios y bienes ligados a la satisfacción de las necesidades básicas y la realización de la dignidad humana y el proyecto de vida-. La solidaridad entonces resultará esencial para contribuir en la superación de las condiciones de desigualdad reconociendo que "quienes están mejor en la sociedad son los llamados a colaborar con aquellos que se encuentran en estado de vulnerabilidad, situación de indefensión o

66 Corte Constitucional, Sentencia C-148 de 2015, de 7 de abril de 2015.

67 Corte Constitucional, Sentencia C-263 de 2011, de 6 de abril de 2011. 
desprotección, o en estado de marginación" por ello "en el contexto de toma de decisiones macroeconómicas y sociales [...] los distintos sectores de la población, en virtud del principio de solidaridad, asumen cargas públicas razonables para permitir que sectores excluidos puedan progresivamente ser incorporados al goce de los beneficios del progreso, lo cual solo se puede lograr mediante la conciencia creciente de la necesidad de cooperar y actuar mancomunadamente para mejorar la calidad de vida de todos los colombianos y superar gradualmente las desigualdades presentes ${ }^{68}$.

Por ello las medidas de intervención del Estado en la economía parten del reconocimiento de que es imperativo mantener las garantías necesarias para que el mercado funcione y se posibilite el intercambio comercial -facilitando la participación de los ciudadanos- en un marco de condiciones que permita el desarrollo y prosperidad económica y la libre competencia. Ese marco se encuentra previsto en la Constitución y su desarrollo le corresponde, de manera principal al legislador, y en desarrollo de su facultad reglamentaria al Ejecutivo en armonía con otras instituciones y entidades. En este sentido, el mercado como un factor real de poder debe estar sometido a la autoridad de aquel, a un sistema de Derecho Constitucional ${ }^{69}$, pues el mercado "no es un fin en sí mismo sino que se encuentra subordinado al logro de unos objetivos mayores fijados por la sociedad" 70 .

Bajo esta perspectiva el reconocimiento que la Norma Fundamental hace de la libertad de empresa, la libre iniciativa privada y la libre competencia económica como garantías para el logro del desarrollo económico y el bienestar general, amén de la dirección de la economía a cargo del Estado, se ajusta a las condiciones que la ESM hace respecto a una opción intermedia entre dos sistemas considerados antagonistas. El Estado en este sistema asume la obligación de promover la libre competencia y la libertad económica en los términos del art. 333 C.P.; reconoce a la empresa y a la iniciativa privada como motores de la economía (art. 333 C.P.); consigna medidas que le permiten limitar, razonable y proporcionalmente las libertades económicas, para cumplir los propósitos constitucionales; promueve la protección del interés general, y considera la realización personal de los

68 Corte Constitucional, Sentencia C-1064 de 2001, de 10 de octubre de 2001.

69 Palacios (1999), p. 53.

70 Uribe y Castillo (2005), p. 229. 
individuos como fin último de la actividad estatal ${ }^{71}$. En este sentido es posible seguir lo planteado por Palacios Mejía cuando afirma la protección y promoción de la libre competencia "es indispensable para que una sociedad pueda conseguir que aquellos recursos de que dispone permitan producir la mayor cantidad de bienes y servicios posibles para sus habitantes"72.

A su vez, y como premisa fundamental reconoce la relevancia, para el mantenimiento del sistema, de un marco normativo que proteja la libre competencia, que prohíba y sancione los comportamientos que los individuos desplieguen en el mercado orientados a restringir condiciones de competencia libre o abuso de su posición de dominio en el mercado (art. 333 inc. $4^{\circ}$ C.P.), que ampare al consumidor.

En este punto es preciso indicar que, de manera expresa, la Economía Social de Mercado no se manifiesta como una finalidad constitucional, sin embargo su existencia está objetivamente asegurada por la combinación de varias "piezas de mosaico" como las libertades económicas, sociales y culturales, aunado a la protección constitucional que se predica del derecho al trabajo (art. 25 C.P.) y la seguridad social (art. 48 C.P.).

Y aunque no es una finalidad explícita, constituye el marco que tendrá que tener en cuenta el legislador al desarrollar los principios, valores y disposiciones generales de contenido económico que consigna la Constitución. El constituyente colombiano consideró que "el orden económico constitucional es ante todo un mandato de configuración legislativa y que por lo tanto la Constitución es neutra desde el punto de vista de la fijación de modelos económicos, pues dicha tarea le corresponde establecerla a la ley"73. Pero no desde la perspectiva de una ley que establezca un sistema económico expreso pues ello excedería las competencias que le han sido asignadas al Congreso, le corresponderá en desarrollo de esas disposiciones, dar marcha a un sistema económico que se ajuste a la realidad económica variable y mutable a través de precisas leyes de intervención que satisfagan los requisitos señalados por el constituyente; tampoco desde la perspectiva de la imposibilidad de ajustar la Constitución Económica a un sistema económico determinado.

71 Corte Constitucional, Sentencia C-251 de 1997, de 28 de mayo de 1997.

72 Palacios (2007a), p. 43.

73 Corte Constitucional, Sentencia C-644 de 2012, de 23 de agosto de 2012. 
El sistema económico que interpreta la Corte Constitucional y que desarrolla el legislador, y las demás autoridades competentes ${ }^{74}$, debe ajustarse a los lineamientos generales que consigna la Constitución y que se convierten en pilares fundamentales que no podrán ser desatendidos so pena de violación a la Constitución. La fijación del sistema económico que, en apariencia se delega en el legislador, no es ilimitada; la interpretación armónica y sistemática que del texto superior se hace permite predicar que el mismo se ajusta a un sistema de Economía Social de Mercado que excluye, entre otros, sistemas de economía dirigida y economía de mercado ${ }^{75}$.

La discrecionalidad entonces no resulta ser ilimitada, razón que permite predicar que, aunque no existe formalmente un sistema constitucional económico, materialmente sí es posible identificar la Constitución de 1991 con el de Economía Social de Mercado al articular las cláusulas que protegen la economía de mercado con aquellas que predican el deber de solidaridad (arts. 1 y 95 C.P.) ${ }^{76}$, subsidiariedad, equidad, eficiencia ${ }^{77}$ e intervención que al Estado le corresponde como director de la economía (art. 334 C.P.).

$74 \mathrm{Al}$ hacer una revisión de la competencia para el desarrollo de la Constitución se advierte un protagonismo especial en el legislador, sin embargo el Ejecutivo también tiene competencias en materias económicas -en los términos del art. 189 No 11 C.P.- pues le corresponde el ejercicio de la potestad reglamentaria aunada a las funciones que en materia de inspección, vigilancia y control que frente a ciertas actividades y respecto a determinados agentes económicos le ha sido encargada. Esta competencia encuentra plena justificación por la complejidad técnica que revisten los asuntos económicos y la necesidad de regulación oportuna, con capacidad de adaptación a la constante mutación de las relaciones económicas. El Presidente de la República, como suprema autoridad administrativa, al tenor del mandato que le impone la ley (art. 189 C.P.), desarrolla esta función de inspección, vigilancia y control mediante la descentralización, desconcentración y delegación de funciones. Para el logro efectivo de este cometido requiere de la creación, a través de leyes del Congreso, de organismos, como las Superintendencias que faciliten esta labor, bajo dirección presidencial.

75 Corte Constitucional, Sentencia C-265 de 1994, de 2 de junio de 1994.

76 El modelo de Estado Social de Derecho legitima la intervención del Estado en la economía, en particular en las relaciones privadas de producción "a través de una política fundada en el principio de solidaridad y en el papel redistributivo del Estado" en el que a aquel le corresponde la "promoción de las condiciones sociales y económicas básicas para el desarrollo autónomo de la persona” al tenor de la Sentencia de la Corte Constitucional C-040 de 1993, de 11 de febrero de 1993.

77 La Sentencia de la Corte Constitucional T-016 de 2007, de 22 de enero de 2007, al reconocer la fundamentalidad del derecho a la salud en el ordenamiento constitucional colombiano hizo énfasis en estos cuatro principios, básicos en un sistema de Economía Social de Mercado, para indicar que en un Estado en el que los recursos son escasos corresponde a aquel desplegar todas las medidas necesarias para garantizar a toda la población la satisfacción de sus propias necesidades y la realización de sus proyectos de vida, en armonía con el principio de dignidad humana, obligación que se hace palmaria respecto de la población 
Ello supone que la indeterminación expresa de un sistema no se traduce en absoluta libertad legislativa pues en esos términos se reduciría el valor normativo de la Constitución Económica, que sería un catálogo de normas programáticas que solo encontrarían desarrollo dependiendo de la voluntad política del momento. El legislador, y en general todas las autoridades encargadas de adoptar decisiones con ese contenido, deben considerar los mandatos económicos y de contenido social que la Constitución imprime como realizaciones del Estado. Respecto al legislador (podrían enmarcarse acá todas las corporaciones públicas de elección popular que registran similar naturaleza) se ha considerado que la tradición democrática, representativa y pluralista que tiene el Congreso le permite ser el escenario para un debate de mayorías y minorías que pueda poner de presente los intereses de cada sector, atender a las necesidades e intereses de la sociedad y responder a la situación económica que necesite atención.

La Corte Constitucional ha señalado que la multiplicidad de preceptos que consigna la Constitución Económica puede reagruparse en torno a tres principios fundamentales: la igualdad material y el principio de progresividad de los derechos sociales; el régimen de protección de las libertades y derechos económicos de las empresas como base de su desarrollo y la libre competencia económica como derecho colectivo, y la internacionalización de las relaciones políticas, económicas, sociales y ecológicas ${ }^{78}$. Estos principios responden a la lógica de una economía de mercado con claros matices intervencionistas en el marco de una economía claramente globalizada. A partir de esta enunciación, es posible hacer una mención de los principios que orientan la actividad económica del Estado y configuran la denominada Constitución Económica colombiana. Todos ellos, sin embargo, no pueden entenderse de forma aislada respecto de las características mencionadas y que constituyen criterios orientadores del sistema constitucional.

\subsubsection{Caracteristicas generales del sistema de Economía Social de Mercado en la jurisprudencia constitucional}

Al tenor de la identificación jurisprudencial del sistema de ESM las características que este sistema posee son:

más necesitada. No obstante esta circunstancia posteriormente la Ley No 1751 de 2015 reconoció el carácter fundamental del derecho a la salud.

78 Corte Constitucional, Sentencia C-644 de 2012, de 23 de agosto de 2012. 
a. Protección constitucional de la economía de mercado: El mercado es un elemento esencial de la Constitución Económica por lo que al Estado le corresponde promover la existencia de mercados competitivos con independencia de que se reserve ciertos servicios actividades económicas. En presencia de mercados competitivos el despliegue de las libertades económicas se producirá de manera más efectiva y los derechos de los consumidores encontrarán menores limitaciones. Como institución su protección deviene en esencial para evitar la eliminación de "uno de los ejes del sistema económico diseñado por el Constituyente que, además, sirve de soporte a valiosos derechos constitucionales" 79 .

Por ello un sistema de ESM como el que acoge -materialmente- la Constitución no se limita simplemente a garantizar una libertad formal de mercado, compromete al Estado a adelantar intervenciones cuando en él se asienten "constelaciones de poder -formalmente inobjetablesque afecten seriamente la competencia" 80 . Esta potestad parte del reconocimiento de que la libre competencia constituye fundamento básico del cual depende la eficiencia superior del mercado en la generación de bienestar social y exige, con relación a los agentes del mercado -oferentes y demandantes- la existencia y respeto de claras señales de mercado a partir de las cuales estos puedan adoptar decisiones racionales respecto de su comportamiento en el mercado. Que existan señales claras, no distorsionadas ni manipuladas, será tarea que corresponda al Estado, por ello se indicaba con anterioridad que la existencia de un régimen normativo claro que reconozca los derechos de propiedad, permita las transacciones, reduzca sus costos y garantice un régimen de responsabilidad en caso de incumplimiento resultan ser esenciales en un sistema de economía de mercado.

La protección que se reconoce al mercado en la Norma superior impide al legislador y a cualquier autoridad u órgano con competencias económicas poder eliminar la libertad económica de acceso al mercado para sujetarse a las leyes de oferta y demanda o poder limitar, sin restricción alguna, los elementos que estructuran la libre competencia económi-

79 Corte Constitucional, Sentencia C-183 de 1998, de 6 de mayo de 1998.

80 Pfaller (1997). 
$\mathrm{ca}^{81}$. El mercado se consolida como la opción que permite realizar el bienestar general y materializar la noción de Estado Social de Derecho; las libertades, garantías y derechos de los ciudadanos encuentran, en gran medida, su realización en aquel.

b. Principio pro igualdad y progresividad de los derechos económicos y sociales: el sistema de ESM armoniza con el modelo de Estado Social de Derecho, los dos persiguen objetivos similares y reconocen la importancia de la actuación del Estado para superar circunstancias de debilidad estructural, esta relación se hace palmaria en Ehmke para quien "el verdadero núcleo de la Economía Social de Mercado reside en la cláusula del Estado Social [...] y en el principio de igualdad [...] como parte del orden fundamental liberal democrático [...]" 82 .

En el sistema acogido por la Constitución colombiana una de sus características definitorias supone la realización del principio de igualdad material que garantice a todos sus ciudadanos el disfrute de sus derechos y libertades. No es posible perder de vista que el ESD emergió como reacción a los sistemas de economía planificada -que anulaban la libertad individual-, y economía de mercado -que libraban al mercado de la tarea de generar bienestar para todos-. En este sistema de Estado "no basta con suponer que el mercado florecerá naturalmente, generando riqueza y bienestar para todos de manera incontenible, espontánea y feliz" 83 sino que comporta una serie de garantías de patrones mínimos dentro de los cuales sea posible vivir dignamente, en un concepto de derecho y no de beneficencia ${ }^{84}$. La realización de la igualdad no queda abandonada a las fuerzas del mercado sino que exige una intervención continua y constante de las autoridades públicas para que esas garantías y patrones se realicen.

Es claro, en consecuencia, el reconocimiento del que parte el constituyente de 1991 al manifestar que la cuestión social estaba al orden del día y que a partir de ello resultaba fundamental reconocer la existencia de

81 Corte Constitucional, Sentencia C-535 de 1997, de 23 de octubre de 1997.

82 Ehmke (2006), p. 346.

83 Botero y Guardo (2004), p. 12.

84 Corte Constitucional, Sentencia C-595 de 1999, de 18 de agosto de 1999. 
profundas desigualdades entre los individuos ${ }^{85}$, respecto de las cuales la promoción de condiciones de igualdad será tarea fundamental del Estado.

c. Dirección general de la economía a cargo del Estado: Es quizás uno de los elementos que permite, en mayor medida, ajustar el sistema constitucional económico con la Economía Social de Mercado, pues esta dirección parte de la base del reconocimiento del mercado como escenario en el que se produce el proceso de intercambio de bienes y servicios ${ }^{86}$, pero reconoce las limitaciones que en términos de satisfacción de necesidades, distribución equitativa de las oportunidades, acceso en condiciones de igualdad real y preservación de un medio ambiente sano limitan la realización de los fines y objetivos del Estado Social de Derecho ${ }^{87}$.

De conformidad con el artículo 334 de la Constitución es claro que la dirección general de la economía le corresponde al Estado y que en desarrollo de esa facultad puede intervenir observando tres condiciones a) la intervención se produce por mandato de la ley, b) recae sobre una serie de actividades expresamente señaladas y c) debe perseguir objetivos concretos y puntuales. En esta disposición, además, es posible entender que esta habilitación puede producirse de manera ex ante o ex post. Este último argumento refuerza el papel que las constituciones de la posguerra le han le han asignado al Estado -y que fue acogido por la Constitución de 1991- al atribuirle competencias y dotarlo de instrumentos para intervenir en la economía no sólo en aquellos casos en que el mercado registra problemas -papel corrector-, sino que se anticipa a ellos para buscar la armonización del desarrollo económico con un orden social justo.

d. Protección y promoción de la libre competencia como derecho colectivo y principio constitucional: La confianza en el mercado como institución más acertada para que se produzca el juego de la oferta y la demanda constituye el rasgo esencial de este sistema, sin embargo para que este proceso pueda cumplirse en condiciones de eficiencia se requiere de la libre competencia económica como institución que permite a los agentes económicos interesados concurrir en pie de igualdad a ofertar bienes y servicios, y en consecuencia cualquier comportamiento, con

85 Corte Constitucional, Sentencia C-566 de 1995, de 30 de noviembre de 1995.

86 Guinard-Hernández (2017), pp. 185-189.

87 Corte Constitucional, Sentencia C-150 de 2003, de 25 de febrero de 2003. 
independencia del sujeto que lo propicie, que esté orientado a falsear o restringir las condiciones de competencia en que debe desenvolverse ese proceso debe ser reprimido y sancionado ${ }^{88}$. La protección y promoción de la libre competencia no es un asunto que pueda confiarse al mercado, por ello tal función corresponde al Estado 89 y, en virtud del mandato constitucional, corresponderá también a los ciudadanos como titulares del derecho individual y colectivo referenciado ${ }^{90}$.

La libre competencia como un derecho, que puede ser alegado por los ciudadanos en caso de vulneración, además incorpora un enfoque garantista ligado a la función que al Estado le ha sido asignada como director general de la economía que le impone la obligación de intervenir cuando advierta que cualquier agente económico despliega o pretenda desplegar cualquier acto, conducta o práctica que pueda menoscabar sus elementos esenciales. Esta precisión se hace partiendo del reconocimiento de que el ejercicio de las libertades económicas que contempla la Constitución necesita un escenario de competencia libre que les permita a los ciudadanos desplegarlas.

La Corte Constitucional ha reconocido que la libre competencia no es un derecho absoluto ${ }^{91}$, esto implica que este derecho tiene límites, que guardan coherencia con el principio de prevalencia del interés general en el marco de las facultades de del Estado para intervenir en la economía en forma proporcionada y razonable a través de la regulación, vigilancia y control ${ }^{92}$.

\section{Conclusiones}

A partir de la línea es posible construir un precedente jurisprudencial más estable respecto a la adopción material de un sistema de Economía Social de Mercado en la Constitución Económica colombiana. Se advierte respecto de esta

\footnotetext{
88 Corte Constitucional, Sentencia C-263 de 2011, de 6 de abril de 2011.

89 Corte Constitucional, Sentencia C-186 de 2011, de 16 de marzo de 2011.

90 Corte Constitucional, Sentencia C-620 de 2016, de 10 de noviembre de 2016.

91 Al respecto las Sentencias de la Corte Constitucional C-915 de 2002, de 19 de octubre de 2002; C-623 de 2004, de 29 de junio de 2004; C-869 de 2010, de 3 de noviembre de 2010, y C-263 de 2013, de 8 de mayo de 2013, sostienen esta posición.

92 Corte Constitucional, Sentencia T-368 de 1995, de 24 de agosto de 1995.
} 
última posición un desarrollo conceptual acertado que se ajusta a los lineamientos constitucionales y permite predicar su correspondencia con los fines del ESD. No obstante lo mencionado, es preciso señalar que, la línea registra movimientos hacia cada uno de los polos por lo que se trata de una interpretación aún en construcción.

Este sistema económico, reconocido materialmente por la jurisprudencia constitucional, prioriza la libertad individual, la libertad de mercado -con todos los derechos y garantías necesarias para su funcionamiento-, la solidaridad y la subsidiariedad. En el sistema mencionado los individuos tienen un papel fundamental como responsables de su propio desarrollo, como protagonistas de su plan de vida, una reafirmación de la protección especial que se reconoce de la dignidad humana como principio y derecho. Se reconoce la necesidad de medidas por parte del Estado destinadas a garantizar la justicia social, la convivencia, el disfrute de los derechos individuales y colectivos, pero se ratifica la necesidad de empoderar a los ciudadanos en torno a la responsabilidad por su propio bienestar, correspondiendo al Estado un papel subsidiario.

A pesar de la consagración constitucional y posterior reconocimiento -por vía jurisprudencial- de múltiples garantías y derechos de contenido económico, resulta clara la imposibilidad de predicar de cualquiera de ellos su carácter absoluto. Si como se ha señalado todos ellos deben interpretarse de manera armónica y sistemática con los pilares del modelo de Estado y el sistema económico, limitaciones y restricciones dadas por la configuración misma del derecho o su posterior desarrollo legislativo pueden ser de recibo, siempre que su núcleo esencial se mantenga incólume.

La capacidad que le ha sido atribuida constitucionalmente al Estado para influir en las variables macroeconómicas es uno de los principales instrumentos con que cuenta este para el logro de sus fines esenciales y encuentra su justificación en la necesidad de armonizar los intereses de los agentes económicos que concurren al mercado y el interés general de la comunidad. El Estado a través de facultades de autorización, vigilancia, supervisión y reglamentación -sujetas a principios de legalidad y observancia plena de la Constitución y la ley- garantiza la realización efectiva de los postulados mínimos del Estado Social de Derecho. En todo caso, el poder de dirección e intervención en la economía exige el cumplimiento de tres condiciones: a) esta se produce por mandato de la ley, b) recae sobre una serie de actividades expresamente señaladas y c) debe perseguir objetivos concretos y puntuales. 
Finalmente este sistema propende a la protección de la libre competencia como principio constitutivo que permite el adecuado funcionamiento del mercado al restringir y sancionar comportamientos abusivos por parte de los agentes económicos y potencia el bienestar de los consumidores y usuarios al crear condiciones de mercado en las que, en principio, todos puedan concurrir para cubrir las necesidades básicas y satisfacer un mínimo vital.

\section{BiBLIOGRAFÍA}

Aguiló Regla, Josep (2004). La Constitución del Estado Constitucional (LimaBogotá, Palestra-Temis).

Alarcón Peña, Andrea (2011). "Los juristas frente a los mercados: herramientas de análisis económico del derecho", en Revista IUSTA, pp. 125-136.

Alarcón Peña, Andrea (2017). "Origen y Características del Modelo de la Economía Social de Mercado”, en Revista Principia Iuris (27), pp. 98-117.

Alarcón Peña, Andrea (2016). "La libre competencia económica en el derecho colombiano: una revisión desde la Economía Social de Mercado y sus implicaciones normativas", en Revista Prolegómenos (37), pp. 109-124.

Álvarez Conde, Enrique (2005). Curso de derecho constitucional. Volumen I. El estado constitucional, el sistema de fuentes, los derechos y las libertades, Vol. I (Madrid, Tecnos).

Anzola, M. (2007). "Corte Constitucional y economía de mercado", en C. M. Molina Betancur, Corte Constitucional y Estado Social de Derecho (Medellín, Universidad de Medellín), pp. 125-137.

ARAGón Reyes, Manuel (1995). Libertades económicas y estado social. (Madrid: McGraw-Hill).

Ariño Ortíz, Gaspar (2003). Principios de Derecho Público Económico. Modelo de Estado, gestión pública, regulación económica (Bogotá, Universidad Externado de Colombia).

Bassols Coma, Martín (1985). Constitución y sistema económico (Madrid: Tecnos). Benítez, Jaime; Cuevas, Tulio; Garzón, Angelino; Guerrero, Guillermo; MaRUlanda, Iván; Perry, Guillermo; Hoyos, Óscar (1991). Asamblea Nacional Constituyente. Informe-Ponencia para primer debate en plenaria. Finalidad Estado Social de Derecho y la Seguridad Social, en Gaceta Constitucional (No 78-mayo). 
Botero Marino, Catalina y Guardo Martínez, Andrea (2004). "Estado Social de Derecho y Economía Social de Mercado en Colombia: algunas ideas preliminares sobre la relación entre la Constitución y la política económica”, en Economía Social de Mercado y Tratado de Libre Comercio en Colombia. Análisis y propuestas sobre el impacto del TLC en la pobreza, los derechos laborales y la pequeña y mediana industria (Bogotá: Fundación Social-Konrad Adenauer Stiftung), pp. 11-56.

Cepeda, Manuel José (2005). Polémicas constitucionales (Bogotá, Legis).

Cidoncha Martín, Antonio (2004). La libertad de empresa en el marco de la economia de mercado: el artículo 38 de la Constitución española, [fecha de consulta: 30 de enero de 2017]. [Disponible en https://www.researchgate.net/ publication/47442072_La_libertad_de_empresa_en_el_marco_de_la_economia_de_mercado_el_articulo_38_de_la_Constitucion_Espanola].

Cortés Nieto, Johanna del Pilar; Ospina Duque, Edgar, y Dueñas, Óscar José (2009). "Derechos económicos, sociales y culturales", en AA.VV., Itinerario de la jurisprudencia colombiana de control constitucional como mecanismo de protección de los derechos humanos (Bogotá, Editorial Universidad del Rosario), pp. 203-352.

Cortés Zambrano, Sonia (2009). "El Estado, la Constitución y la Economía de Mercado", en Revista virtual via in viniendi et iudicandi, pp. 1-44.

DuQue, Justino (1977). "Iniciativa privada y empresa”, en Sánchez Agesta, Constitución y Economía. La ordenación del sistema conómico en las Constituciones occidentales. (Madrid, Centro de Estudios y Comunicación Económica), pp. 49-78.

Echeverri Uruburu, Álvaro (2012). "La Constitución de 1991. De una democracia restringida y bloqueada a una democracia social y participativa”, en AA.VV., Historia Constitucional colombiana, 2a ed., Vol. II (Bogotá, Ediciones Academia Colombiana de Jurisprudencia Colección Investigaciones), pp. 439-488.

Ehmke, Horst (enero-junio de 2006). "Economía y Constitución”. Revista de Derecho Constitucional Europeo (5), pp. 329-380.

Eucken, Walter (2011 (1952)). "Las fuerzas influyentes: El Estado", en A. Müller-Armack, L. Erhard, B. Herzog, D. H. Ernste, W. Eucken, M. Marktanner, N. Kloten, Una mirada a la teoría, a los modelos económicos y a la economía de mercado. Reflexiones teóricas para Bolivia (La Paz, Fundación Konrad Adenauer Stiftung), pp. 77-90. 
García Echeverría, Santiago (1978). "El orden económico en la Constitución", en Revista Libre empresa: Nueva Revista Nacional de Economia (8), pp. 7-58. García Lozada, Nelson y Almonacid Sierra, Juan Jorge (1999). "La Constitución Económica de 1991: instrumento jurídico para la democratización de la economía colombiana", en Pensamiento Jurídico. Revista de Teoría del Derecho y Análisis Jurídico (10), pp. 135-170.

Guinard-Hernández, David (2017). 'La 'regulación económica' como instrumento de dirección estatal de la economía”, en Revista Digital de Derecho Administrativo (18), pp. 177-224.

HäBerle, Peter (1997). "Incursus. Perspectiva de una doctrina constitucional del mercado: siete tesis de trabajo", en Revista Pensamiento Constitucional, 4(4), pp. 13-29.

Hart, Herbert Lionel Adolphus (1995). El concepto de Derecho (Buenos Aires. Abeledo-Perrot).

Hesse, Konrad (1983). Escritos de Derecho Constitucional (Madrid, Centro de Estudios Constitucionales).

Julio Estrada, Alexey (2002). Economía y ordenamiento constitucional, en AA.VV., Teorías jurídicas y económicas del Estado (Bogotá, Universidad Externado de Colombia), pp. 171-198.

Leguizamon Acosta, William (2000). Derecho Constitucional económico (Bogotá, Ediciones Jurídicas Gustavo Ibáñez).

López Díaz, Karen (2017). La constitucionalización de la economía social de mercado en Colombia, en Revista Advocatus (28), pp. 151-174.

López Medina, Diego Eduardo (2006). Interpretación constitucional, 2a ed. (Bogotá, Consejo Superior de la Judicatura).

Loewenstein, Karl (1982). Teoría de la Constitución, 2a ed. reimpr. (Barcelona, Ariel).

Maestro Buelga, Gonzalo (2002). "Constitución económica e integración europea”, en Revista de Derecho Político (54), pp. 33-111.

Martín-Retortillo, Sebastián (1988). Derecho Administrativo Económico (Madrid, La Ley).

Martín-Retortillo, Sebastián (2000). "La 'Constitución económica' en el texto de la Constitución española de 1978, en García de Enterría, E. Constitución y constitucionalismo hoy (Venezuela: Fundación Manuel García Pelayo), pp. 149-174. 
Mejía Quintana, Óscar (21 de octubre de 2010). "La constitucionalización de la mentira. Dominación y exclusión en la Constitución del 91", [fecha de consulta: 2 de febrero de 2017]. [Disponible en: http://www.espaciocritico.com/sites/ all/files/artcls/a0049_om-a02.pdf].

Menéndez Menéndez, Aurelio (1985). “Constitución, sistema económico y Derecho Mercantil”, en Revista Hacienda Pública Española (94), pp. 47-77.

Neumann, Franz (1987). "On the precondittions and the legal concept of an economic constitution", en A. \& Unwin, Social democracy and the rule of law, (Londres, HarperCollins Publishers Ltd.), pp. 44-65.

Ochoa Cardich, César (1985). "Constitución y economía de mercado", en Revista de la Facultad de Derecho PUCP (39), pp. 229-267.

Palacios Mejía, Hugo (1999). La Economía en el Derecho Constitucional Colombiano (Bogotá, Derecho vigente).

Palacios Mejía, Hugo (2007a). "La Constitución y la especialización de las funciones de protección a la competencia en materia de servicios públicos domiciliarios", en Revista Con-texto (21), pp. 39-56.

Palacios Mejía, Hugo (2007b). "Notas acerca de la facultad de regular la economía en la Constitución de 1991”, en Revista de Derecho Público, pp. 39-55.

PAPIER, Juan Jorge (1996). "Ley fundamental y orden económico", en M. B. Benda, Manual de Derecho Constitucional (Madrid, Marcial Pons Ediciones Jurídicas), pp. 561-612.

Pfaller, Alfred (1997). El estado en la economía social de mercado: el modelo y la realidad alemana, [fecha de consulta: 10 de agosto de 2016] [Disponible en http://library.fes.de/fulltext/stabsabteilung/00074.htm\#I0].

Pérez González-Rubio, Jesús (1991). Ponencia para Segundo Debate. "Régimen económico, libre empresa e intervención del Estado", en Gaceta de la Corte Constitucional (Bogotá, Imprenta Nacional).

Perry, Guillermo (2011). La Constitución de 1991 y el Desarrollo Económico y Social, [fecha de consulta: 21 de junio de 2016]. [Disponible en http:// focoeconomico.org/2011/06/21/la-constitucion-de-1991-y-el-desarrolloeconomico-y-social/].

Quinche Ramírez, Manuel Fernando (2009). Derecho Constitucional colombiano. De la Carta de 1991 y sus reformas. (Bogotá, Universidad del Rosario).

SÁchICA, Luis Carlos (1991). "Título XII Del Régimen económico y de la Hacienda pública”. En Sáchica, L.C. y Vidal Perdomo, J., Aproximación 
critica a la Constitución de 1991 (Bogotá, Cámara de Comercio de Bogotá), pp. 147-160.

SÁnchez Torres, Carlos Ariel (2001). "El modelo económico y el debilitamiento del poder presidencial en Colombia. Constitución Política de 1991”, en AA.VV., La Constitución por construir. Balance de una década de cambio institucional (Bogotá, Universidad del Rosario), pp. 285-297.

SÁnchez Torres, Carlos Ariel (2007). Constitución Económica, 1a ed. (Bogotá, Consejo Superior de la Judicatura).

SÁnchez Torres, Carlos Ariel e Ibáñez Parra, Óscar (2007 A). "El TLC, el derecho colectivo de la competencia y las acciones populares", en RinCÓN Cárdenas, E.; Santamaría Ariza, E., El tratado de libre comercio, la integración comercial y el derecho de los mercados (Bogotá, Universidad del Rosario), pp. 339-392.

Santaella Quintero, Héctor (2001). "El modelo económico en la constitución de 1991", en Revista Derecho del Estado (11), pp. 85-93.

Schmitт, Carl (1998). La defensa de la Constitución, Segunda ed. (Madrid, Tecnos).

Schneider, H. P. (1991 (1983)). "Aplicación directa y eficacia indirecta de las normas constitucionales", en SchneIder, H. P., Democracia y Constitución (Madrid, Centro de Estudios Constitucionales), pp. 71-115.

STÖBER, Rolf (1992). Derecho administrativo económico, $1^{\text {a }}$ ed. (Traducción S. González-Varas Ibáñez, Madrid, Ministerio para las Administraciones Públicas).

Tomás y Valiente, Francisco (1994). "La resistencia constitucional y los valores". En Revista Doxa. Cuadernos de Filosofía del Derecho (15-16), pp. 635-650.

Torres Ávila, Jheison (2012). El mandato del Estado social de derecho en la Constitución colombiana: los derechos sociales y el minimo vital, $1^{\text {a }} \mathrm{ed}$. (Bogotá, Universidad Santo Tomás).

Torres Ávila, Jheison (2017). "La teoría del garantismo: poder y constitución en el Estado contemporáneo", en Revista de Derecho Universidad del Norte, pp. 148-176.

Uprimny Yepes, Rodrigo (2002). "Constitución de 1991, Estado Social y Derechos Humanos: promesas incumplidas, diagnósticos y perspectivas". En AA. VV., El debate a la Constitución (Bogotá, Universidad Nacional de Colombia-ILSA), pp. 55-72. 
Uprimny Yepes, Rodrigo y Rodríguez, César (2005). “Constitución y modelo económico en Colombia: Hacia una discusión productiva entre economía y derecho", en Revista Debates de Coyuntura Económica, pp. 24-40.

Uprimny YePes, Rodrigo y Rodríguez Villabona, Andrés Abel (2008). Interpretación judicial (Bogotá, Escuela Judicial Rodrigo Lara Bonilla).

Vergottini, G. D. (2012). "La constitución económica italiana: pasado y actualidad”, en Revista Teoría y Realidad Constitucional (29), pp. 339-354.

\section{Jurisprudencia Corte Constitucional de Colombia}

Corte Constitucional de Colombia, Auto 057 de 2004, de 29 de enero de 2004. Corte Constitucional de Colombia, Sentencia C-032 de 2017, de 25 de enero de 2017.

Corte Constitucional de Colombia, Sentencia C-035 de 2016, de 8 de febrero de 2016.

Corte Constitucional de Colombia, Sentencia C-037 de 1996, de 5 de febrero de 1996.

Corte Constitucional de Colombia, Sentencia C-040 de 1993, de 11 de febrero de 1993.

Corte Constitucional de Colombia, Sentencia C-074 de 1993, de 25 de febrero de 1993.

Corte Constitucional de Colombia,, Sentencia C-107 de 2013, de 6 de marzo de 2013.

Corte Constitucional de Colombia, Sentencia C-1064 de 2001, de 10 de octubre de 2001.

Corte Constitucional de Colombia, Sentencia C-1041 de 2007, de 4 de diciembre de 2007.

Corte Constitucional de Colombia, Sentencia C-1107 de 2001, de 24 de octubre de 2001.

Corte Constitucional de Colombia, Sentencia C-148 de 2015, de 7 de abril de 2015.

Corte Constitucional de Colombia, Sentencia C-150 de 2003, de 25 de febrero de 2003.

Corte Constitucional de Colombia, Sentencia C-186 de 2011, de 16 de marzo de 2011. 
Corte Constitucional de Colombia, Sentencia C-183 de 1998, de 6 de mayo de 1998.

Corte Constitucional de Colombia, Sentencia C-197 de 2012, de 14 de marzo de 2012.

Corte Constitucional de Colombia, Sentencia C-228 de 2010, de 24 de marzo de 2010.

Corte Constitucional de Colombia, Sentencia C-263 de 2011, de 6 de abril de 2011.

Corte Constitucional de Colombia, Sentencia C-263 de 2013, de 8 de mayo de 2013.

Corte Constitucional de Colombia, Sentencia C-265 de 1994, de 2 de junio de 1994.

Corte Constitucional de Colombia, Sentencia C-284 de 2015, de 13 de mayo de 2015.

Corte Constitucional de Colombia, Sentencia C-288 de 2012, de 18 de abril de 2012.

Corte Constitucional de Colombia, Sentencia C-313 de 2013, de 23 de mayo de 2013.

Corte Constitucional de Colombia, Sentencia C-332 de 2000, de 22 de marzo de 2000.

Corte Constitucional de Colombia, Sentencia C-350 de 2009, de 29 de mayo de 2009.

Corte Constitucional de Colombia, Sentencia C-392 de 2007, de 23 de mayo de 2007.

Corte Constitucional de Colombia, Sentencia C-398 de 1995, de 7 de septiembre de 1995.

Corte Constitucional de Colombia, Sentencia C-426 de 2002, de 29 de mayo de 2002.

Corte Constitucional de Colombia, Sentencia C-478 de 1998, de 9 de septiembre de 1998.

Corte Constitucional de Colombia, Sentencia C-517 de 1992, de 15 de septiembre de 1992.

Corte Constitucional de Colombia, Sentencia C-524 de 1995, de 16 de noviembre de 1995. 
Corte Constitucional de Colombia, Sentencia C-535 de 1997, de 23 de octubre de 1997.

Corte Constitucional de Colombia, Sentencia C-566 de 1995, de 30 de noviembre de 1995.

Corte Constitucional de Colombia, Sentencia C-595 de 1999, de 18 de agosto de 1999.

Corte Constitucional de Colombia, Sentencia C-615 de 2002, de 8 de agosto de 2002.

Corte Constitucional de Colombia, Sentencia C-616 de 2001, de 13 de junio de 2001.

Corte Constitucional de Colombia, Sentencia C-620 de 2016, de 10 de noviembre de 2016.

Corte Constitucional de Colombia, Sentencia C-644 de 2012, de 23 de agosto de 2012.

Corte Constitucional de Colombia, Sentencia C-713 de 2008, de 15 de julio de 2008.

Corte Constitucional de Colombia, Sentencia C-776 de 2003, de 9 de septiembre de 2003.

Corte Constitucional de Colombia, Sentencia C-815 de 2001, de 2 de agosto de 2001.

Corte Constitucional de Colombia, Sentencia C-818 de 2005, de 9 de agosto de 2005.

Corte Constitucional de Colombia, Sentencia C-820 de 2006, de 4 de octubre de 2006.

Corte Constitucional de Colombia, Sentencia C-830 de 2010, de 20 de octubre de 2010.

Corte Constitucional de Colombia, Sentencia C-837 de 2013, de 20 de noviembre de 2013.

Corte Constitucional de Colombia, Sentencia C-865 de 2004, de 7 de septiembre de 2004.

Corte Constitucional de Colombia, Sentencia C-869 de 2010, de 3 de noviembre de 2010.

Corte Constitucional de Colombia, Sentencia C-909 de 2012, de 7 de noviembre de 2012 . 
Corte Constitucional de Colombia, Sentencia C-915 de 2002, de 19 de octubre de 2002.

Corte Constitucional de Colombia, Sentencia C-983 de 2005, de 26 de septiembre de 2005.

Corte Constitucional de Colombia, Sentencia C-978 de 2010, de 1 de diciembre de 2010.

Corte Constitucional de Colombia, Sentencia T-016 de 2007, de 22 de enero de 2007.

Corte Constitucional de Colombia, Sentencia T-028 de 1994, de 31 de enero de 1994.

Corte Constitucional de Colombia, Sentencia T-263 de 1993, de 7 de julio de 1993.

Corte Constitucional de Colombia, Sentencia T-308 de 1995, de 13 de julio de 1995.

Corte Constitucional de Colombia, Sentencia T-368 de 1995, de 24 de agosto de 1995.

Corte Constitucional de Colombia, Sentencia T-380 de 1993, de 13 de septiembre de 1993.

Corte Constitucional de Colombia, Sentencia T-425 de 1992, de 24 de junio de 1992.

Corte Constitucional de Colombia, Sentencia T-505 de 1992, de 28 de agosto de 1992.

\section{Jurisprudencia Consejo de Estado}

Consejo de Estado, Sección Tercera, de 4 de septiembre de 2015. Rad. 1100103-26-000-2015-00103-00 (54549) M.P. Santofimio, Jaime Orlando.

Consejo de Estado, Sección Tercera, de 9 de julio de 2014. Rad. 66001-23-31000-2009-00087-02 (47830) M.P. Santofimio, Jaime Orlando.

Consejo de Estado, Sección Tercera, de 21 de febrero de 2007. 25000-23-25000-2004-00413-01(AP). M.P. Fajardo Gómez, Mauricio.

Consejo de Estado, Sección Tercera, Rad. 25000-23-27-000-2004-0088801(AP). M.P. Correa Palacio, Ruth Stella.

Consejo de Estado, Sección Tercera Rad. 25000-23-26-000-2000-01335-01 (28.505) M.P. Santofimio Gamboa, Jaime Orlando. 
